\title{
RIG-I-like helicases induce immunogenic cell death of pancreatic cancer cells and sensitize tumors toward killing by $\mathrm{CD}^{+} \mathrm{T}$ cells
}

\author{
This article has been corrected since Online Publication and a corrigendum appears in this issue
}

\author{
P Duewell $^{1,2}$, A Steger ${ }^{1}$, H Lohr ${ }^{1}$, H Bourhis ${ }^{1}$, H Hoelz $^{1}$, SV Kirchleitner ${ }^{1}$, MR Stieg ${ }^{1}$, S Grassmann ${ }^{1}$, S Kobold ${ }^{1}$, JT Siveke ${ }^{3}$, S Endres ${ }^{1}$ \\ and M Schnurr*,1,2
}

Pancreatic cancer is characterized by a microenvironment suppressing immune responses. RIG-I-like helicases (RLH) are immunoreceptors for viral RNA that induce an antiviral response program via the production of type I interferons (IFN) and apoptosis in susceptible cells. We recently identified RLH as therapeutic targets of pancreatic cancer for counteracting immunosuppressive mechanisms and apoptosis induction. Here, we investigated immunogenic consequences of RLH-induced tumor cell death. Treatment of murine pancreatic cancer cell lines with RLH ligands induced production of type I IFN and proinflammatory cytokines. In addition, tumor cells died via intrinsic apoptosis and displayed features of immunogenic cell death, such as release of HMGB1 and translocation of calreticulin to the outer cell membrane. RLH-activated tumor cells led to activation of dendritic cells (DCs), which was mediated by tumor-derived type I IFN, whereas TLR, RAGE or inflammasome signaling was dispensable. Importantly, $\mathrm{CD} 8 \alpha^{+}$DCs effectively engulfed apoptotic tumor material and cross-presented tumorassociated antigen to naive $\mathrm{CD8}^{+} \mathrm{T}$ cells. In comparison, tumor cell death mediated by oxaliplatin, staurosporine or mechanical disruption failed to induce DC activation and antigen presentation. Tumor cells treated with sublethal doses of RLH ligands upregulated Fas and MHC-I expression and were effectively sensitized towards Fas-mediated apoptosis and cytotoxic T lymphocyte (CTL)-mediated lysis. Vaccination of mice with RLH-activated tumor cells induced protective antitumor immunity in vivo. In addition, MDA5-based immunotherapy led to effective tumor control of established pancreatic tumors. In summary, RLH ligands induce a highly immunogenic form of tumor cell death linking innate and adaptive immunity.

Cell Death and Differentiation (2014) 21, 1825-1837; doi:10.1038/cdd.2014.96; published online 11 July 2014

Patients diagnosed with pancreatic cancer face a poor prognosis due to early metastasis and therapy resistance, resulting in a 5-year survival rate of only $6 \%$. $^{1}$ Treatment options for inoperable tumors are limited and offer little benefit for the patients. But even after tumor resection most patients relapse and succumb to their disease, as evidenced by a 5year survival rate of $20 \%{ }^{2}$ Novel treatment strategies such as immunotherapy are being investigated. ${ }^{3}$ Pancreatic cancer is characterized by an immunosuppressive microenvironment, which is mediated by cytokines such as TGF- $\beta$, modulation of antigen-presenting cells, impaired T-cell effector function as well as recruitment of regulatory $T$ cells and myeloid-derived suppressor cells. ${ }^{4}$ Immunosuppressive factors correlate with a poor prognosis for patients with pancreatic cancer. ${ }^{5-8}$ On the other hand, T-cell infiltrates of the tumor were found to be a positive prognostic factor. ${ }^{9}$ The major challenge for immunotherapy will be to counteract immunosuppressive mechanisms for tipping the balance toward productive immune responses against the tumor.

Tumor cell death occurs spontaneously in fast growing tumors or is induced by specific therapies, such as cytotoxic agents or irradiation. Several forms of cell death, such as apoptosis, necrosis, autophagy, mitotic catastrophe and senescence can be discriminated. It appears that the conditions leading to tumor cell death dictate immunological consequences. $^{10,11}$ In most circumstances, cell death is immunologically silent, leading to tolerance rather than immunity. In specific situations, dying cells release immunogenic signals to the cell surface or the extracellular space leading to the activation of antigen-presenting cells, such as DCs, and facilitating antigen uptake and presentation. These signals are collectively called danger-associated molecular

\footnotetext{
${ }^{1}$ Abteilung für Klinische Pharmakologie and Center for Integrated Protein Science Munich (CIPS M), Medizinische Klinik und Poliklinik IV, Klinikum der Universität München, Ziemssenstrasse 1, München, Germany; ${ }^{2}$ Medizinische Klinik und Poliklinik IV, Klinikum der Universität München, Ziemssenstrasse 1, München, Germany and ${ }^{3}$ Medizinische Klinik, Klinikum rechts der Isar, Technische Universität München, Ismaningerstrasse 22, München, Germany

${ }^{*}$ Corresponding author: M Schnurr, Abteilung für Klinische Pharmakologie, Klinikum der Universität München, Ziemssenstrasse 1, 80336 München, Germany. Tel: +49 895160 5300; Fax: +49 895160 7300; E-mail: max.schnurr@med.uni-muenchen.de

Abbreviations: ATP, adenosine triphosphate; ASC, apoptosis-associated speck-like protein containing a CARD; CTL, cytotoxic T lymphocytes; CXCL10, C-X-C motif chemokine 10; DC, dendritic cell; HMGB1, high-mobility group protein B1; Hsp70, heat shock protein 70; IFN interferon; IFNAR Type I IFN receptor; IL-1, interleukin-1; IRF-3, IFN regulatory factor 3; MDA5 melanoma differentiation-associated protein 5; MHC-I, major histocompatibility complex class I; NLRP3, NOD-like receptor family, pyrin domain containing 3; P2 $\times 7$, P2X purinoceptor 7; RAGE, receptor for advanced glycation endproducts; PARP, poly ADP ribose polymerase; poly(l:C) polyinosinic:polycytidylic acid; ppp-RNA, RNA containing a 5'-triphosphate modification; RIG-I, retinoic acid-inducible gene 1; RLH RIG-I-like helicases; siRNA, small interfering RNA; TLR, Toll-like receptor; TNF- $\alpha$, tumor necrosis factor- $\alpha$

Received 15.11.13; revised 06.5.14; accepted 05.6.14; Edited by P Salomoni; published online 11.7.14
} 
patterns (DAMPs) and include calreticulin exposure on the outer cell membrane, release of heat shock proteins, HMGB1, DNA, RNA, ATP and uric acid crystals, or the secretion of proinflammatory cytokines, such as IL-1 and IL-6. ${ }^{12}$ Evidence has accumulated that certain chemotherapeutic drugs, which were traditionally considered to mediate antitumor effects via their antiproliferative properties, induce an immunogenic form of cell death leading to tumor-directed immunity. ${ }^{11,13}$

Immune responses against viruses share many features with those against tumors. Mimicking a viral infection can be exploited for tumor immunotherapy. Double-stranded viral RNA is recognized by cytosolic pattern recognition receptors called RIG-I-like helicases (RLH), including retinoic acidinducible gene I (RIG-I) and melanoma differentiationassociated antigen 5 (MDA5). ${ }^{14-16}$ Synthetic RLH ligands include 5'-triphosphate RNA (ppp-RNA) for RIG-I, and polyinosinic:polycytidylic acid (poly(l:C)) for MDA5. RLH initiate a signaling cascade mediated by IFN regulatory factor 3 (IRF-3), IRF-7 and NF- $\kappa$ B, leading to an antiviral response program characterized by the production of type I IFN and other innate immune response genes. ${ }^{17,18}$ In addition, RLH signaling induces intrinsic apoptosis in tumor cells, which are highly susceptible, as compared with nonmalignant cells. ${ }^{19,20}$ $\mathrm{RLH}$ ligands have been evaluated as therapeutic agents in preclinical tumor models for melanoma, ovarian cancer and pancreatic cancer. ${ }^{19,21-24}$ Therapeutic efficacy was enhanced by combining RNAi-mediated gene silencing with RIG-I activation in a single RNA molecule. ${ }^{21,24}$ A ppp-siRNA targeting the anti-apoptotic protein $\mathrm{Bcl}-2$ to promote tumor apoptosis showed therapeutic efficacy in experimental melanoma. ${ }^{24}$ In this model, the antitumor effect was dependent on NK cells. To counteract tumor-induced immunosuppression, our group generated a ppp-siRNA silencing TGF- $\beta 1$, which showed therapeutic efficacy in an orthotopic model of pancreatic cancer. ${ }^{21}$ Interestingly, with this approach CD8 ${ }^{+} \mathrm{T}$ cells mediated antitumor efficacy. Others reported that treatment of human ovarian cancer cells with RLH ligands resulted in phagocytosis of apoptotic tumor cells by monocyte-derived DCs and DC activation. ${ }^{22,23}$ Together, these findings indicate that RLH-induced tumor cell death may promote adaptive immunity against tumors. However, mechanisms leading to DC activation and the impact on tumor antigen cross-presentation by DCs, which defines immunogenic cell death, have not been explored.

In this study, we investigated the effects of RLH-induced tumor cell death on DC activation, antigen uptake and crosspresentation of tumor antigen by primary murine DC populations. We also studied mechanisms leading to DC activation using mice deficient in pathways of TLR, RAGE, inflammasome and type I IFN signaling. In addition, we assessed the immunogenicity and therapeutic efficacy of RLH-based immunotherapy in two different mouse models for pancreatic cancer.

\section{Results}

RLH ligands induce cytokine release and apoptosis of pancreatic cancer cells. RLH ligands have been shown to induce the release of type I IFN in cancer cells mediated by IRF-3/7 and NF- $\kappa$ B signaling. ${ }^{19,21-23}$ To confirm intact RLH signaling in pancreatic cancer cells, we transfected Panc02 cells with ppp-RNA or poly(l:C), which induced IFN- $\beta$ mRNA expression as well as CXCL10 and IL-6 secretion in a dose-dependent manner (Figure 1a and Supplementary Figures $1 \mathrm{a}$ and $\mathrm{b}$ ). In addition, treatment of Panc02 tumor cells with RLH ligands resulted in cell death (Figure $1 \mathrm{~b}$ and Supplementary Figure 1c). RNA lacking a $5^{\prime}$-triphosphate modification (OH-RNA) was ineffective in this respect. These effects were strictly dependent on cytosolic delivery of the RLH ligands (data not shown). Silencing of RIG-I or MDA5 expression in tumor cells with siRNA significantly reduced cell death (Figure 1c). Similar findings were obtained with the pancreatic cancer cell line T110299 derived from a Ptf1a-Cre, LSL-Kras ${ }^{\mathrm{G} 12 \mathrm{D}}$, LSL-Trp53 ${ }^{\mathrm{fl} / \mathrm{R} 172 \mathrm{H}}$ mouse $^{25}$ (Supplementary Figure 2). Cell death occurred via intrinsic apoptosis, which was confirmed by assessing caspase- 9 activation by confocal microscopy and cleavage of poly ADP ribose (PARP), a main target of the effector caspase-3 (Figures 1d and e). ${ }^{26,27}$ In line with a previous report identifying MDA5 as an inducer of autophagy, we detected the autophagosomal marker LC3-II in poly(I:C)-treated tumor cells (Figure 1f). ${ }^{28}$ Together, these results indicate that RLH signaling in Panc02 cells results in a proinflammatory form of tumor cell death.

RLH activation leads to features associated with immunogenic cell death and sensitizes tumor cells towards Fas- and CTL-mediated killing. We next investigated whether RLH activation induces characteristics associated with immunogenic cell death. ${ }^{12} \mathrm{RLH}$ activation resulted in a marked upregulation of $\mathrm{MHC}-\mathrm{I}$ molecules and the death receptor CD95 (Fas) on Panc02 and T110299 tumor cells (Figures $2 \mathrm{a}$ and $\mathrm{b}$ and Supplementary Figure 2). ${ }^{20,21}$ In addition, we observed translocation of calreticulin to the cell surface, which has been implicated to facilitate uptake of apoptotic tumor cells by DCs (Figure 2c and Supplementary Figure 1e). ${ }^{29}$ Time course experiments revealed that calreticulin exposure was found on early apoptotic cells (annexin $\mathrm{V}^{+} \mathrm{PI}^{-}$) (Supplementary Figure 1d). Moreover, typical DAMPs, such as HMGB1 and hsp70, were released in significant amounts by $\mathrm{RLH}$-activated tumor cells as late signs of immunogenic cell death (Figures 2d and e).

To assess whether Fas expression correlates with susceptibility to Fas-mediated apoptosis, we incubated RNA-treated tumor cells with an activating Fas $\mathrm{mAb}$ and assessed viability. $\mathrm{RLH}$ ligands potently sensitized tumor cells towards Fasmediated killing in a dose-dependent manner (Figure 2f). Next, we assessed whether increased MHC-I expression correlates with susceptibility towards CTL-mediated lysis. To this end, we treated OVA-expressing Panc02 cells (PancOVA) with sublethal doses of RLH ligands and measured tumor cell lysis by OVA-specific CTL cells from OT-I mice. RLH ligands significantly sensitized tumor cells towards CTL-mediated killing (Figure $2 \mathrm{~g}$ ), whereas no killing was observed for the parental cell line Panc02, confirming antigen specificity (data not shown).

Tumor cells treated with RLH ligands induce DC activation. A key feature of immunogenic cell death is activation of DCs, which regulate adaptive immune 

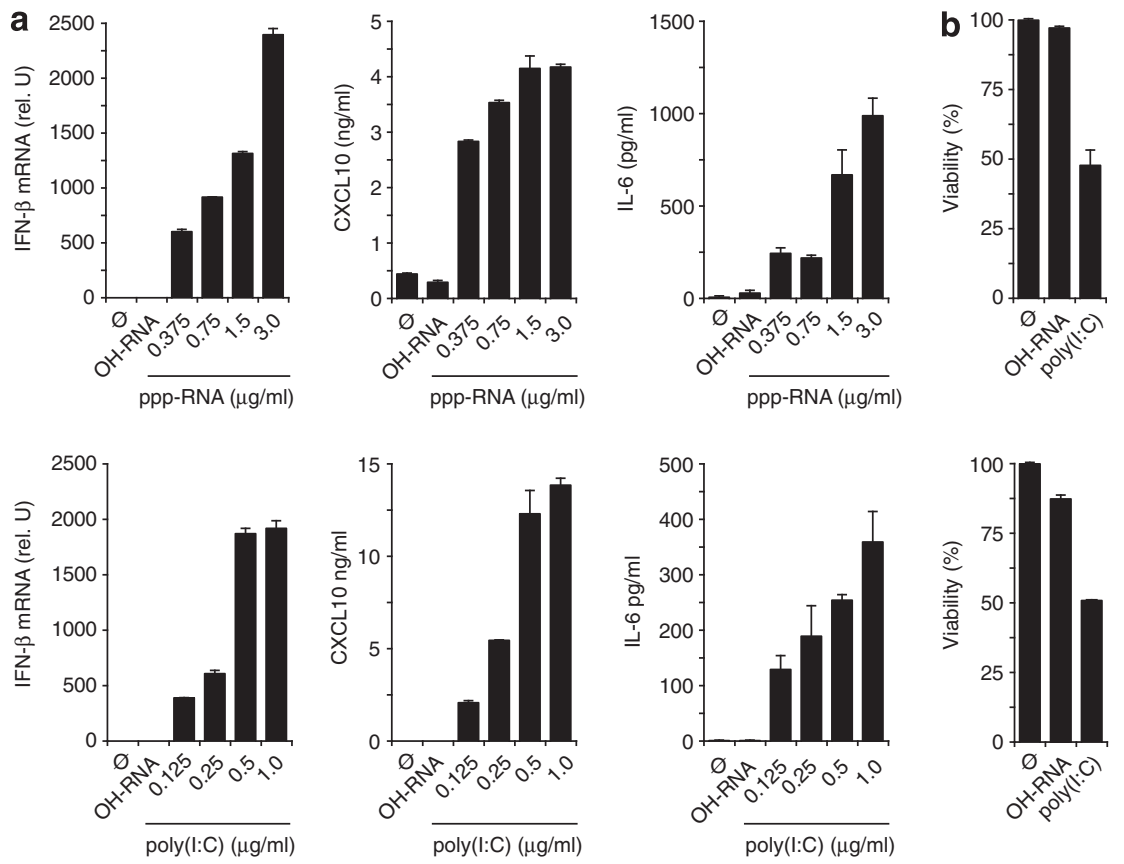

C
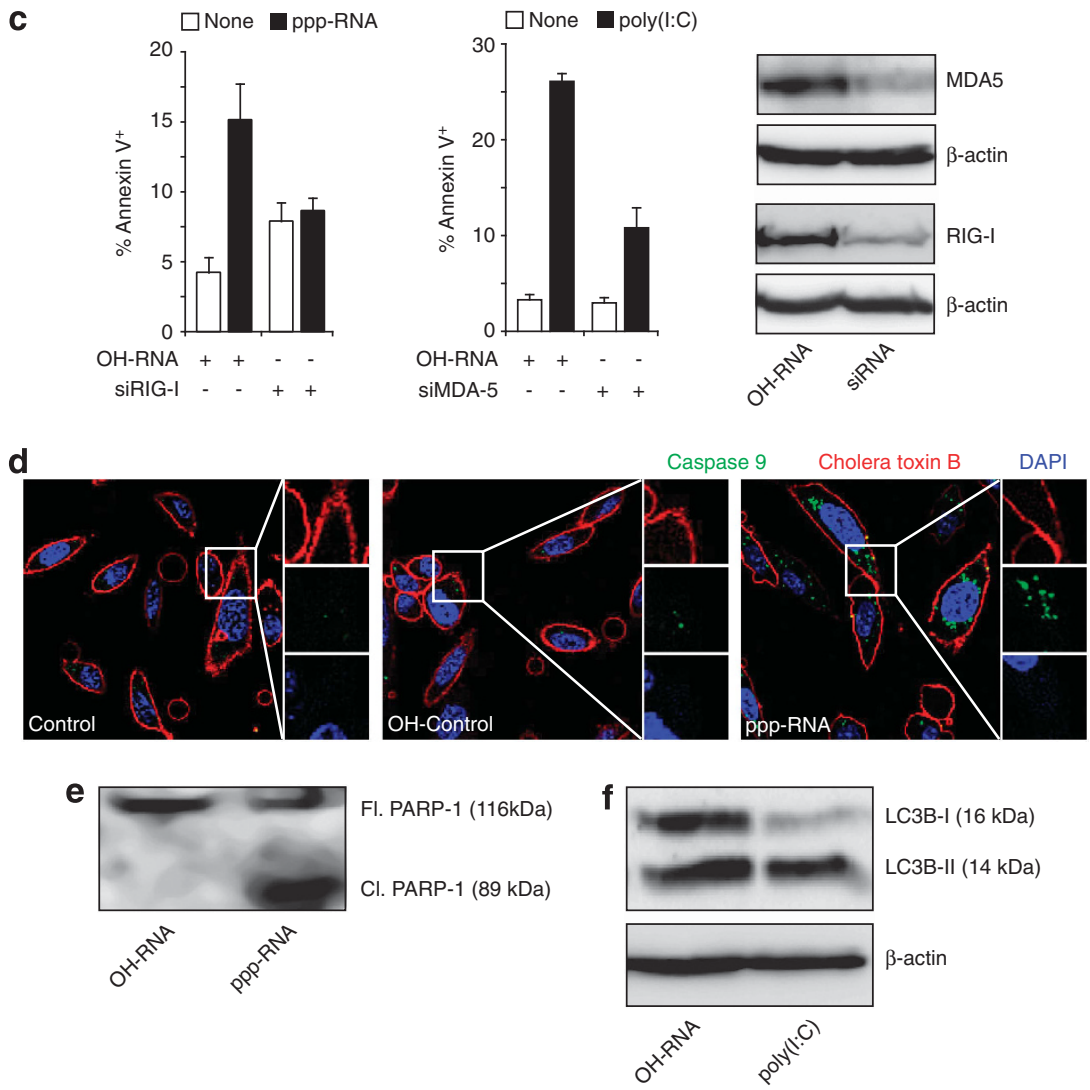

Figure $1 \mathrm{RLH}$ activation induces secretion of proinflammatory cytokines and induction of apoptosis in murine pancreatic cancer cells. (a) Panc02 cells were stimulated with indicated amounts of ppp-RNA, poly(l:C) or left untreated. OH-RNA served as transfection control. IFN- $\beta$ levels were analyzed with qRT-PCR relative to HPRT and secretion of CXCL10 or IL-6 was measured with ELISA; (b) Panc02 cells were stimulated with RNA ( $24 \mathrm{~h}$ for poly(l:C) and $48 \mathrm{~h}$ for ppp-RNA) and viability was assessed by FACS analysis using annexin V/PI staining; (c) Panc02 cells were incubated with siRNA specific for RIG-I or MDA5 for $24 \mathrm{~h}$ and subsequently stimulated with ppp-RNA or poly(l:C). Induction of apoptosis was measured by annexin V/PI staining. Silencing efficacy, as assessed by western blot, is shown; (d) activated caspase-9 (green) was visualized using green FLICA caspase-9 assay kit. Cell membranes were costained with cholera toxin B subunit (red) and nuclei with DAPI (blue); (e and f) Panc02 cells were treated as indicated for $48 \mathrm{~h}$. Full length PARP-1 (116 kDa) and the cleaved large fragment of PARP-1 (89 kDa) (e) as well as the autophagy markers LC3B-I and LC3B-II (f) were analyzed by western blot. Results are representative of at least three independent experiments 

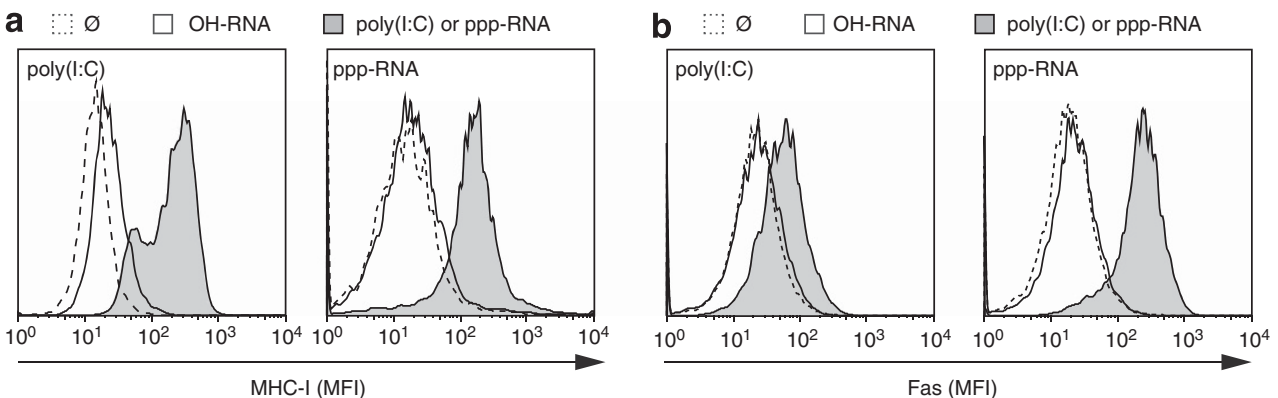

C
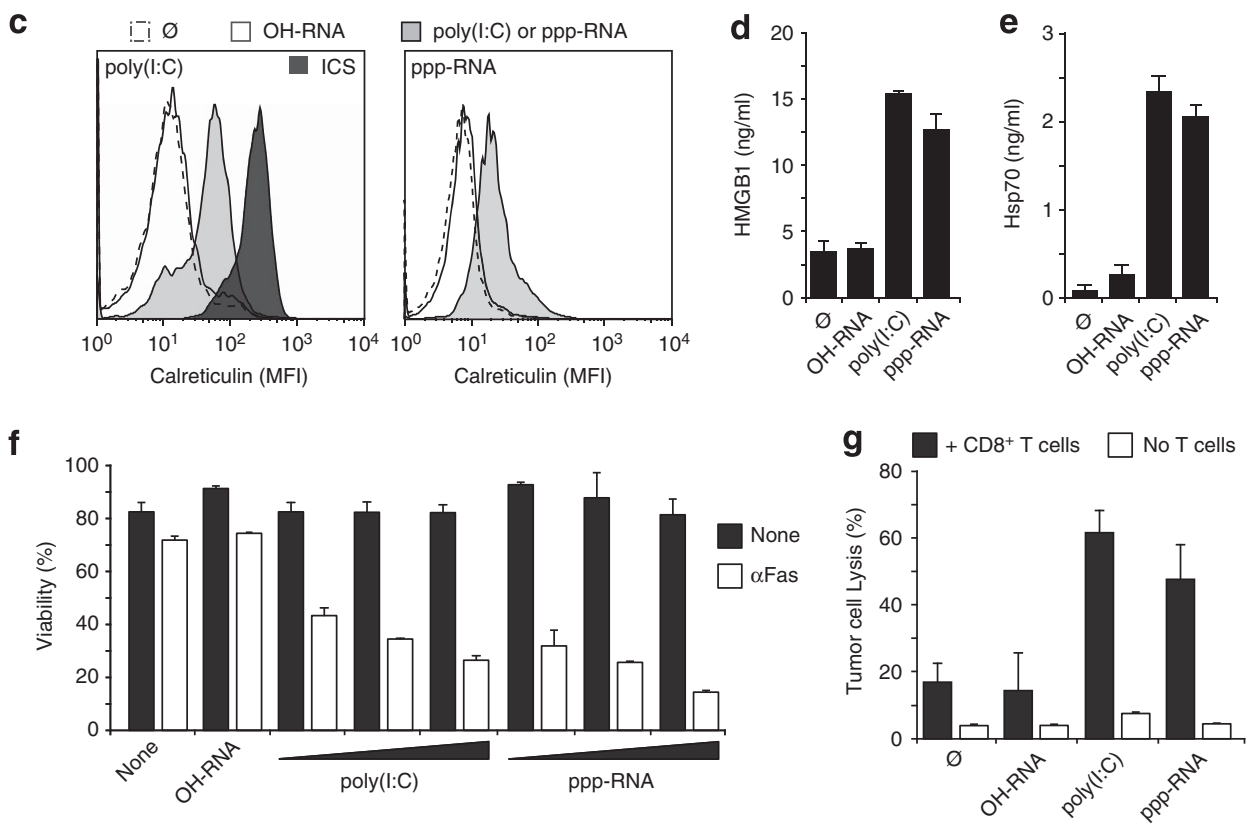

Figure 2 RLH activation induces characteristics of immunogenic cell death and sensitizes tumor cells towards Fas- and CTL-mediated killing. (a-e) Panc02 cells were treated with RLH ligands for $24 \mathrm{~h}$ or left untreated. Surface expression of MHC-I (a), Fas (b) and calreticulin (c) was assessed with FACS analysis; (d and e) release of HMGB1 and $\mathrm{Hsp70}$ in supernatants of RNA-treated tumor cells was measured with ELISA after $48 \mathrm{~h}$; (f) tumor cells were stimulated for $12 \mathrm{~h}$ with RNA as indicated (50, 100, 200 $\mathrm{ng} / \mathrm{ml}$ for poly(l:C) and 500, 1000, $2000 \mathrm{ng} / \mathrm{ml}$ for ppp-RNA) and subsequently stimulated with anti-Fas mAb (clone Jo2; $1 \mu \mathrm{g} / \mathrm{ml}$ ) for another $24 \mathrm{~h}$. Viability was assessed by annexin V/PI staining as double negative cell fraction; $(\mathbf{g})$ lytic activity of OT-I T cells cocultured with RNA-treated PancOVA tumor cells for $6 \mathrm{~h}$ was assessed with an LDH-based cytotoxicity assay. As control, LDH release in the absence of T cells was measured. Representative results out of three independent experiments are shown

responses against the dying cells. The DC system comprises several subsets with specialized functions. The conventional $\mathrm{CD} 8 \alpha^{+}$DC subset is the key DC population inducing T-cell responses against viral or tumor antigens due to its ability to cross-present exogenous antigen on MHC-I molecules to $\mathrm{CD}^{+}{ }^{+}$T cells. $^{30}$ To assess the impact of RLH-induced cell death on DC activation, we isolated DC populations from mice, in which DCs were in vivo expanded by Flt3L secreting B16 cells. $^{31}$ This allowed us to investigate conventional $\mathrm{CD} 8 \alpha^{+}$and $\mathrm{CD} 8 \alpha^{-}$CD $11 \mathrm{c}^{\text {high }} \mathrm{DCs}$, as well as $\mathrm{B220}{ }^{+}$ $\mathrm{CD}_{11 c^{+}}$plasmacytoid DCs (pDCs) (Figure 3a). Coculture of $\mathrm{RLH}$-activated Panc02 cells with DCs induced upregulation of costimulatory molecules (CD80, CD86) and the early activation marker CD69 on all DC subtypes within $12 \mathrm{~h}$. This effect was most pronounced for CD $8 \alpha^{+}$DCs (Figures 3b and c). The possibility that residual RLH ligands still present in the culture media mediated DC activation was ruled out using DCs generated from MDA5- and IRF-3/7-deficient mice, which showed similar CD86 expression levels as DCs from wild-type mice (Figure 3d).
We next assessed the influence of apoptotic tumor cell exposure on DC cytokine and chemokine production. We were able to detect high levels of IL-6 and CXCL10, but not TNF- $\alpha$, IL-1 $\beta$ or IL-12p70 (Figures $3 e$ and $f$ and data not shown). Levels of IL-6 and CXCL10 were significantly higher in cocultures as compared with tumor cells alone, indicative of predominant production by DCs, which was confirmed by intracellular cytokine staining (Figure $3 \mathrm{~g}$ ).

DC maturation is mediated by a soluble factor released from RLH-activated tumor cells. As CD $8 \alpha^{+}$DCs are key players inducing $\mathrm{CD}^{+}{ }^{+} \mathrm{T}$-cell responses, we focused our attention on this DC population. First, we compared the degree of DC activation in tumor cocultures with other known DC activating stimuli. RLH-activated tumor cells induced CD86 upregulation more efficiently as compared with the TLR4 ligand LPS or the TLR9 ligand CpG ODN (Figure 4a and data not shown). In contrast, neither tumor cell lysates (induced by freeze-thawing or hypotonic lysis) nor treatment of tumor cells with staurosporine or the cytotoxic drug 

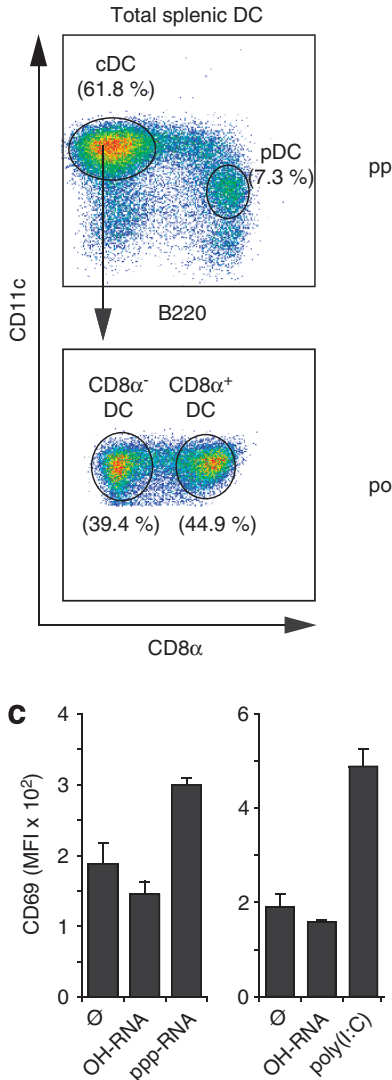

d

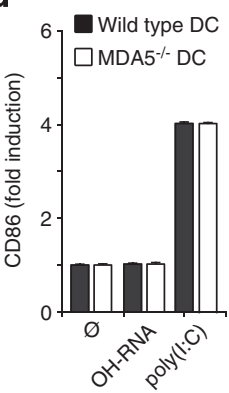

f

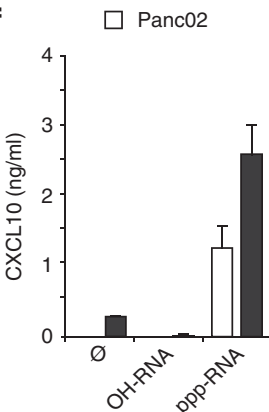

b

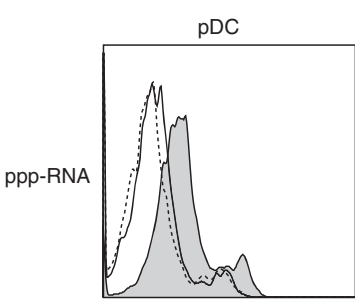

OH-RNA

$\square$ ppp-RNA or poly(l:C) CD8a- DC

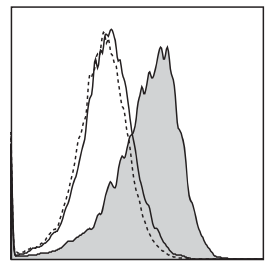

CD8 $\mathrm{a}^{+} \mathrm{DC}$

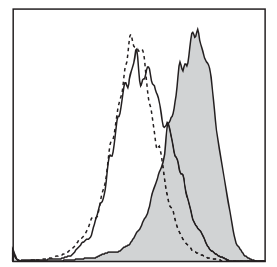

poly $(\mathrm{I}: \mathrm{C})$
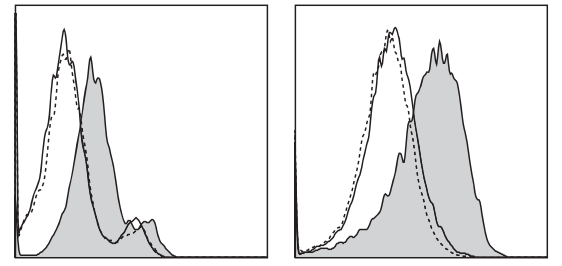

CD86 (MFI)
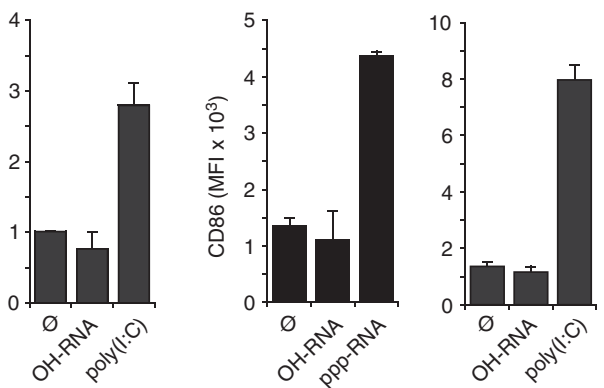

e

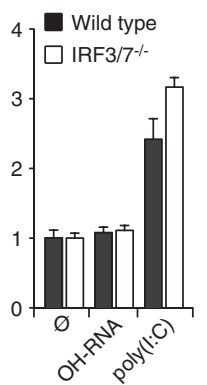

Panc02 + DC

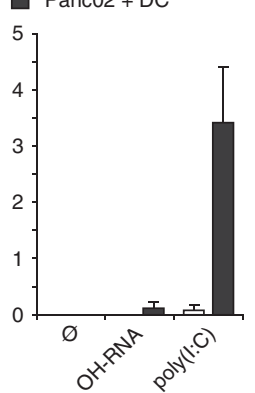

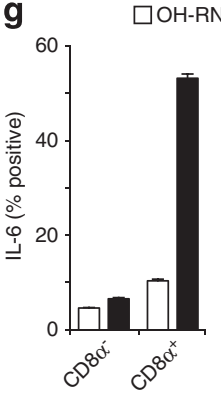

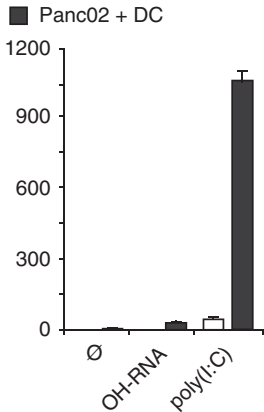

Figure 3 RLH-treated tumor cells induce DC activation. Panc02 cells were left untreated or stimulated with RNA as indicated before coculture with freshly isolated

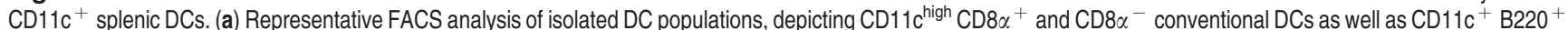
pDCs; (b) CD86 surface expression of different DC subsets after $12 \mathrm{~h}$ exposure to RLH-treated tumor cells; (c) expression levels of CD69, CD80 and CD86 on CD8 $\alpha^{+}$DCs; (d) expression levels of CD86 on CD8 $\alpha^{+}$DCs isolated from wild-type, MDA5- or IRF-3/7-deficient mice exposed to poly(I:C)-treated tumor cells; (e and f) secretion of IL-6 and CXCL10 in supernatants of tumor cells and tumor cell/DC cocultures; $(\mathbf{g})$ intracellular staining of IL-6 and CXCL10 in DC subsets. The results are representative of two (d, $\mathbf{f}, \mathbf{g})$ or three independent experiments (a-c, e) 
oxaliplatin induced significant CD86 upregulation (Figure 4a). DC activation was mediated by a soluble tumor-derived factor secreted into the supernatant (Figure 4b). Pre-treatment of supernatants with benzonase, DNAse, RNAse $\mathrm{A}$ or $\mathrm{H}$ did not affect CD86 expression, indicating that DC activation is not mediated by nucleic acids released from damaged tumor cells (Figure 4b). In contrast, boiling the supernatant or treatment of tumor cells with cycloheximide, which inhibits protein biosynthesis, abrogated CD86 upregulation (Figures 4c and d).

DC activation is independent of TLR, RAGE or inflammasome signaling but involves type I IFN. Apoptotic cells can release multiple types of DAMP leading to DC activation. ${ }^{10}$ Release of HMGB1 from tumor cells undergoing apoptosis or necrosis has been shown to mediate DC activation via TLR2/4 and RAGE signaling. ${ }^{32}$ As RLH-treated tumor cells released high levels of HMGB1 (Figure 2d), we explored DC activation in DCs from mice lacking the TLR adaptor proteins MyD88 or TRIF, TLR4, TLR2/4, as well as RAGE (Figures $5 a$ and b). DC from these mice showed comparable levels of CD86 expression as wild-type mice, arguing against involvement of HMGB1 or other TLR ligands in DC activation. Previously, a role for the NLRP3 inflammasome pathway in DC activation in response to apoptotic tumor cells was reported. ${ }^{33}$ We therefore studied DCs from mice lacking NLRP3, the adaptor molecule ASC, the P2X7 receptor or the effector molecule IL-18. Again, no defect in DC activation was seen in these mice, arguing against inflammasome involvement (Figure 5c).

As RLH-activated tumor cells produced IL- 6 and IFN- $\beta$ (Figure 1a), we assessed the role of these cytokines in DC activation. Adding recombinant IFN- $\alpha$ or IFN- $\beta$ to the supernatant of untreated tumor cells induced CD86 upregulation by CD $8 \alpha^{+}$DCs, whereas IL-6 was inefficient and had no additional effect in combination with type I IFN (Figure 5d). To further explore the role of type I IFN, we added IFN receptor neutralizing $\mathrm{mAb}$ (anti-IFNAR) to the DC-tumor cell cocultures, which effectively inhibited CD86 upregulation (Figure 5e). Finally, DCs derived from IFNAR-deficient mice lacked CD86 upregulation in response to RLH-activated tumor cells (Figure 5f). Together, these findings indicate that type I IFN released from RLH-activated tumor cells is the key factor mediating DC activation.

CD8 $\alpha^{+}$DCs efficiently engulf apoptotic tumor cells and cross-present tumor-associated antigen to $\mathrm{CD}^{+}$ T cells. As immunogenic cell death is defined by the induction of an adaptive immune response to antigens derived from the
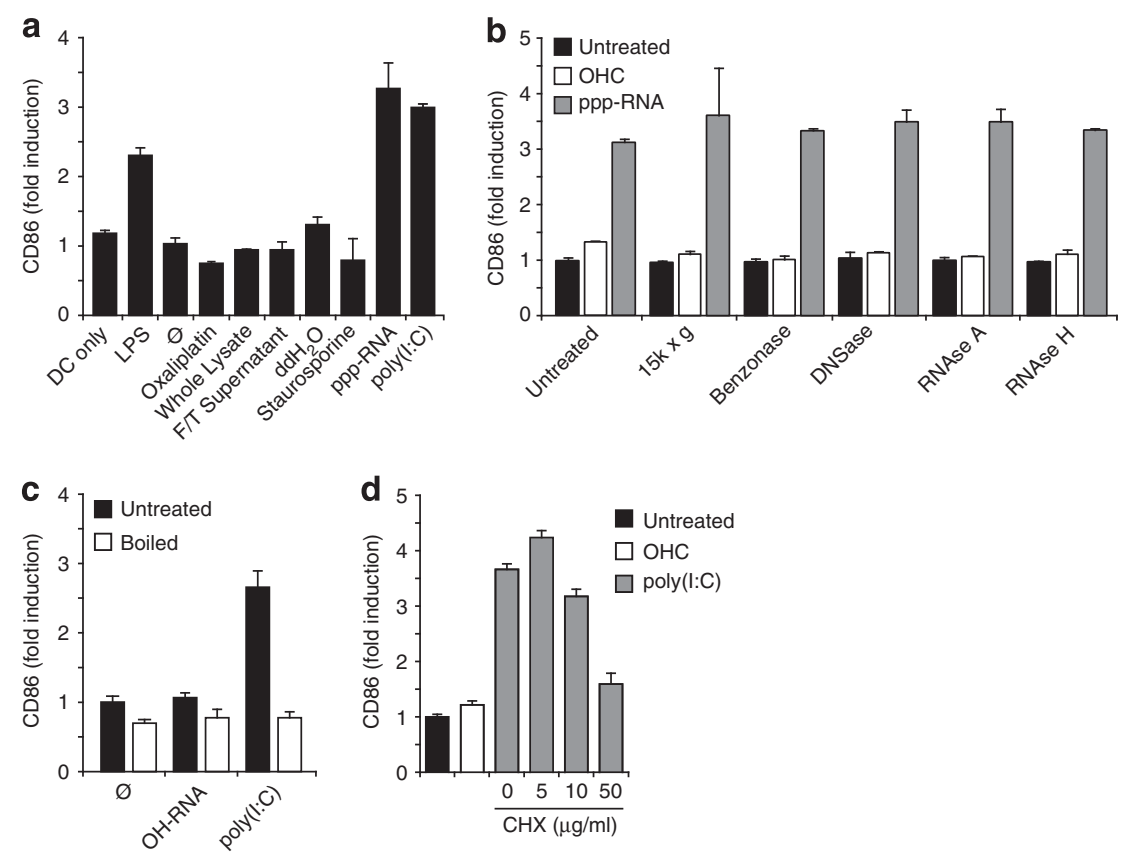

Figure 4 DC activation after exposure to RLH-treated tumor cells is mediated by a soluble tumor-derived factor. (a) Panc02 cells were treated as indicated to induce apoptosis and subsequently cocultured with CD8 $\alpha^{+}$DCs. CD86 surface expression of DCs was analyzed by flow cytometry; (b and $\mathbf{c}$ ) tumor cell supernatant from RNA-treated Panc02 cells was collected and handled as indicated before addition to CD8 $\alpha^{+}$DC cultures; (b) influence of high -speed centrifugation at $15000 \mathrm{~g}$ for $10 \mathrm{~min}$, Benzonase, DNAse, RNAse A and $\mathrm{H}$ treatment of supernatants; (c) influence of boiling of the tumor cell supernatants; (d) influence of tumor cell incubation with cycloheximide $(\mathrm{CHX})$ during RNA stimulation. The results are representative of three independent experiments

Figure 5 DC activation in response to RLH-activated tumor cells is mediated by type I IFN, but independent of TLR, RAGE or inflammasome signaling. (a-c) Expression levels of CD86 on CD8 $\alpha^{+}$DCs isolated from wild-type mice incubated with supernatant from poly(l:C)-treated tumor cells were compared with DCs of (a) MyD88-, TRIF-, TLR4-, TLR2/4deficient, (b) RAGE-deficient, (c) NLRP3-, P2X7-, ASC- and IL-18-deficient mice; (d) tumor cells were treated with RNA as indicated and supernatants were collected. Exogenous IL$6(10 \mathrm{ng} / \mathrm{ml})$, IFN- $\alpha(1000 \mathrm{U} / \mathrm{ml})$, IFN- $\beta(1000 \mathrm{U} / \mathrm{ml})$ or a combination of IL- 6 and IFN were added to the supernatants and transferred to CD8 $\alpha^{+}$DC cultures. CD86 expression of DCs was analyzed; (e) DCs were incubated either with a type IFN receptor (IFNAR) neutralizing or the corresponding control lgG antibody for $2 \mathrm{~h}$ before the addition of tumor cell supernatants; (f) CD86 expression of CD24 high $C D 11 b^{\text {low }}$ CD45RA - DCs (CD8 $\alpha$ CDCs equivalents) generated from bone marrow cultures in the presence of rmFIt3L from IFNARdeficient and respective wild-type mice after exposure to tumor cell supernatant. The results are representative of three independent experiments 
a

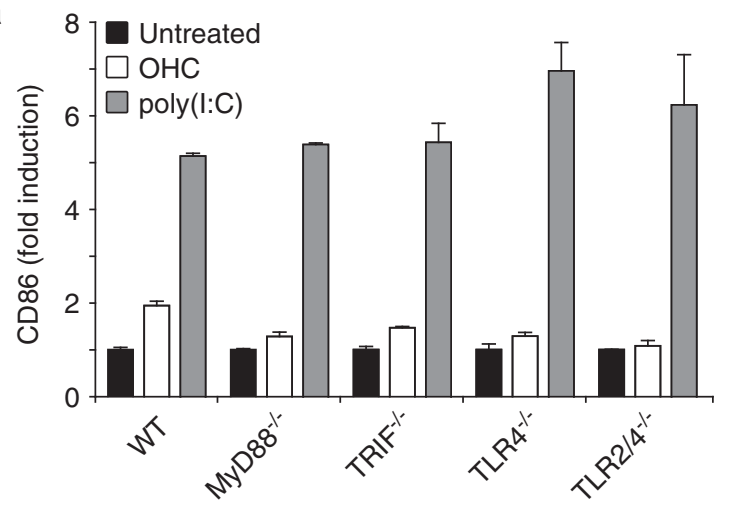

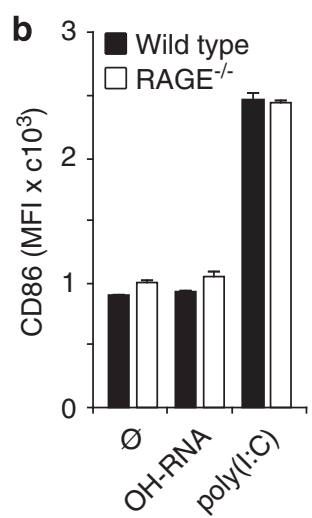
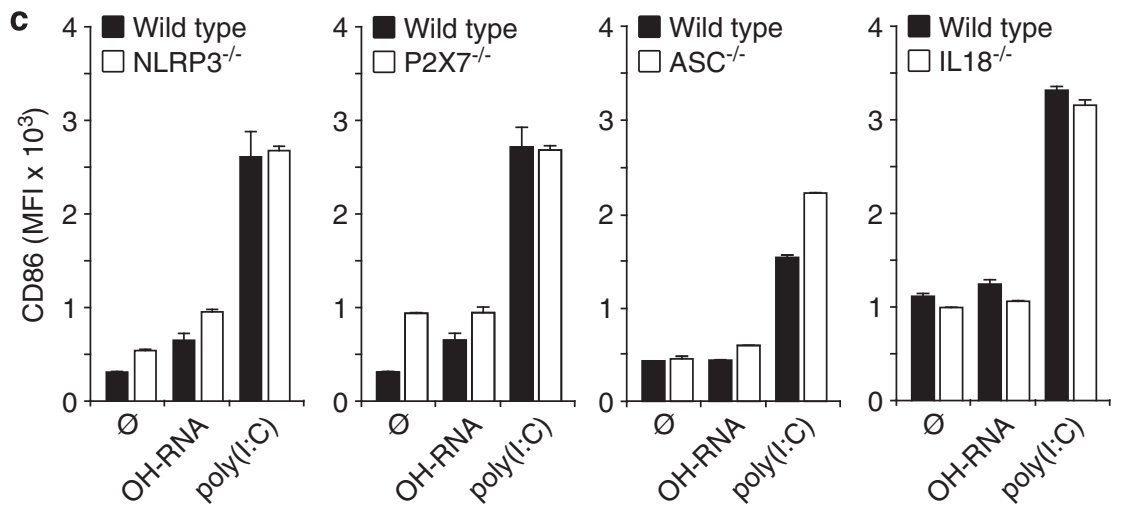

d $2.0_{7} \square$ Untreated $\square$ OH-RNA $\square$ poly(I:C)
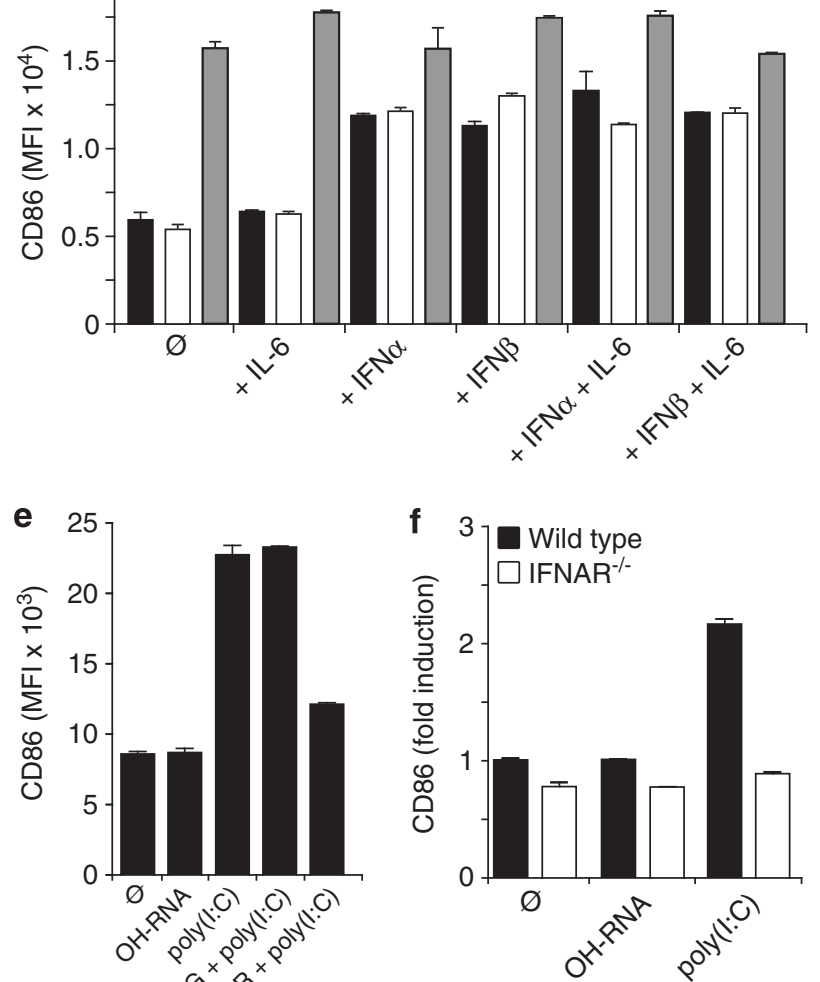
dying cell, we next studied antigen uptake and presentation by DCs. To this end we stained PancOVA cells with CFSE and treated them with RLH ligands, staurosporine or cytotoxic agents. Similar levels of apoptosis were observed for PancOVA and wild-type Panc02 cells (data not shown). Splenic DCs were added to tumor cells and antigen uptake was assessed by flow cytometry. CD $8 \alpha^{+}$DCs, but not pDCs or CD8 $\alpha^{-}$DCs, efficiently engulfed antigen derived from RLH-activated tumor cells (Figure 6a). Antigen uptake was prevented by ice cooling or cytochalasin D, an inhibitor of actin polymerization (Figure $6 \mathrm{~b}$ ). In contrast, induction of tumor cell death with freeze-thaw cycles, hypotonic lysis, oxaliplatin or staurosporine failed to induce efficient antigen uptake by DCs (Figure 6c). To assess antigen crosspresentation, we stained CD $8 \alpha^{+}$and CD $8 \alpha^{-}$DCs from the cocultures with an $\mathrm{mAb}$ recognizing the OVA epitope SIINFEKL in the context of $\mathrm{H}-2 \mathrm{~Kb}$. Correlating with antigen uptake, only $\mathrm{CD} 8 \alpha^{+}$DCs significantly cross-presented SIINFEKL on MHC-I molecules (Figure 6d). In line with this finding, CD $8 \alpha^{+}$DCs but not CD $8 \alpha^{-}$DCs induced proliferation of naive $\mathrm{CD}^{+} \mathrm{OT}-\mathrm{I}$ T cells confirming their ability to crosspresent tumor-associated antigen and to activate naive cytotoxic T cells (Figure 6e). Of note, DCs loaded with tumor cell lysates or apoptotic tumor cells treated with oxaliplatin or staurosporine were incapable of inducing significant T-cell proliferation (Figure 6f). Taken together, RLH activation induces a potent form of immunogenic tumor cell death facilitating both antigen uptake and cross-presentation by DCs.

RLH-induced cell death induces efficient antitumor immunity in vivo. A hallmark of immunogenic cell death is the induction of tumor-specific immunity in vivo. ${ }^{13}$ First, we assessed whether prophylactic vaccination with apoptotic tumor cells mediates protection from subsequent tumor challenge. Apoptotic Panc02 cells, with apoptosis induced by poly(l:C) or staurosporine, were injected s.c. into the left flank of C57BL/6 mice. A week later mice where challenged
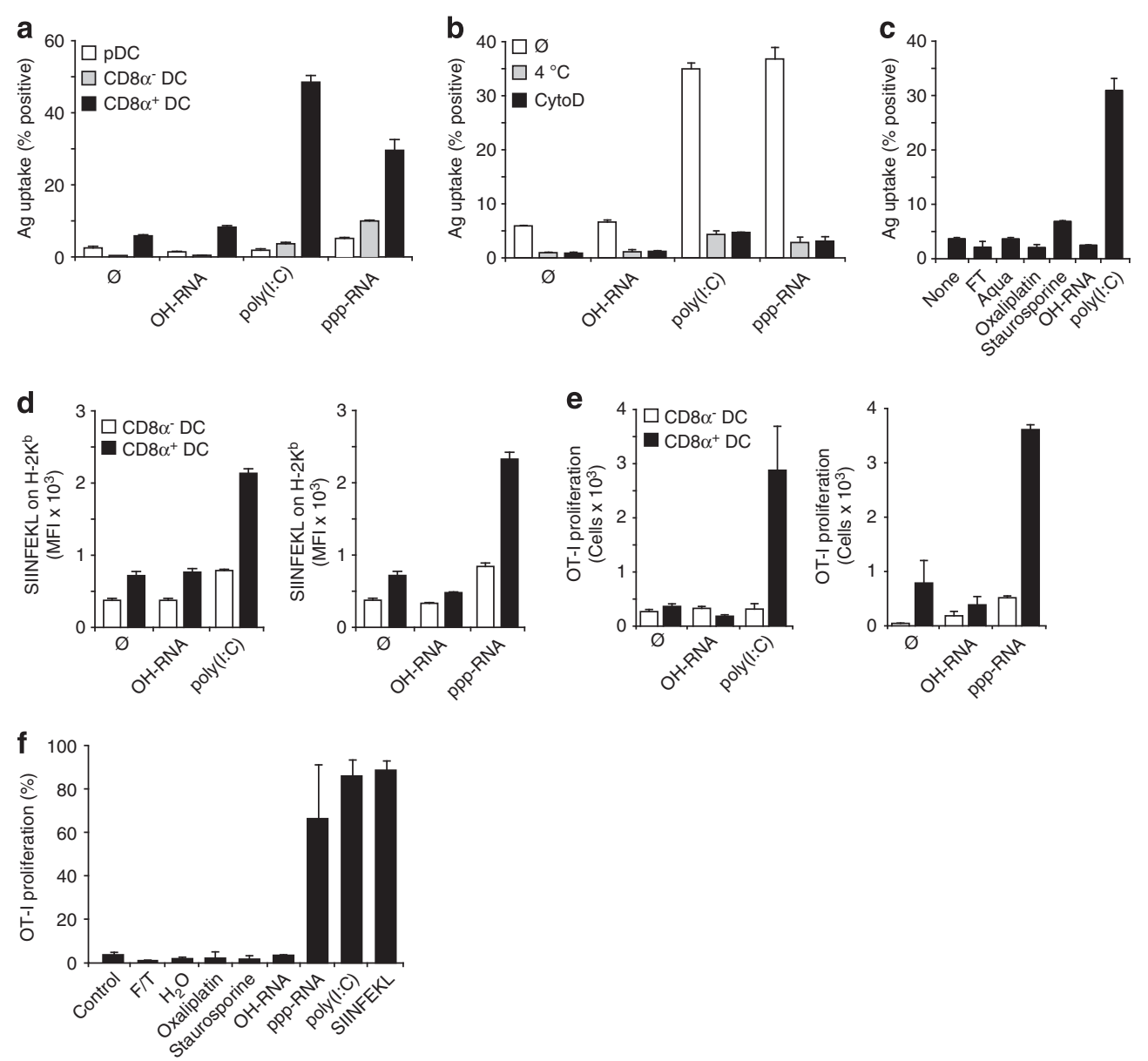

Figure $6 \mathrm{CD} 8 \alpha^{+}$DCs internalize and cross-present tumor antigen from RLH-activated tumor cells to CD8 ${ }^{+} \mathrm{T}$ cells. (a-c) Panc02 cells were labeled with CFSE and treated with RNA as indicated. Total splenic DCs were added to the tumor cell culture for $3 \mathrm{~h}$ and antigen uptake by different DC populations was analyzed with flow cytometry (CFSE positivity); (b) influence of ice cooling or cytochalasin D on antigen uptake by CD8 $\alpha^{+} \mathrm{DCs}$; (c) influence of different modes of cell death on antigen uptake by CD8 $\alpha^{+}$ DCs; (d) quantification of SIINFEKL peptide $\left(\mathrm{OVA}_{257-264}\right)$ bound to $\mathrm{H}-2 \mathrm{~Kb}$ (MHC-I) on CD8 $\alpha^{-}$and CD8 $\alpha^{+}$DCs after coculture with RNA-treated OVA-expressing Panc02 tumor cells; (e) the ability of CD8 $\alpha^{-}$and CD8 $\alpha^{+}$DC populations cocultured with RNA-treated PancOVA tumor cells to induce proliferation of naive CFSE-labeled OT-I T cells was analyzed by flow cytometry after three days; (f) PancOVA cells were treated as indicated and CD $8 \alpha^{+}$DCs were added for $3 \mathrm{~h}$. DCs were harvested and cocultured with naive, CFSE-labeled OT-I T cells for 3 days. OT-I proliferation was analyzed by flow cytometry. The results are representative of two or three independent experiments 
with viable Panc02 cells injected into the right flank. Six out of eight mice that had been vaccinated with RLH-activated tumor cells rejected their tumors and an additional mouse showed growth retardation (Figure 7a). In contrast, all mice that had received staurosporine-treated tumor cells or PBS developed progressive tumors.
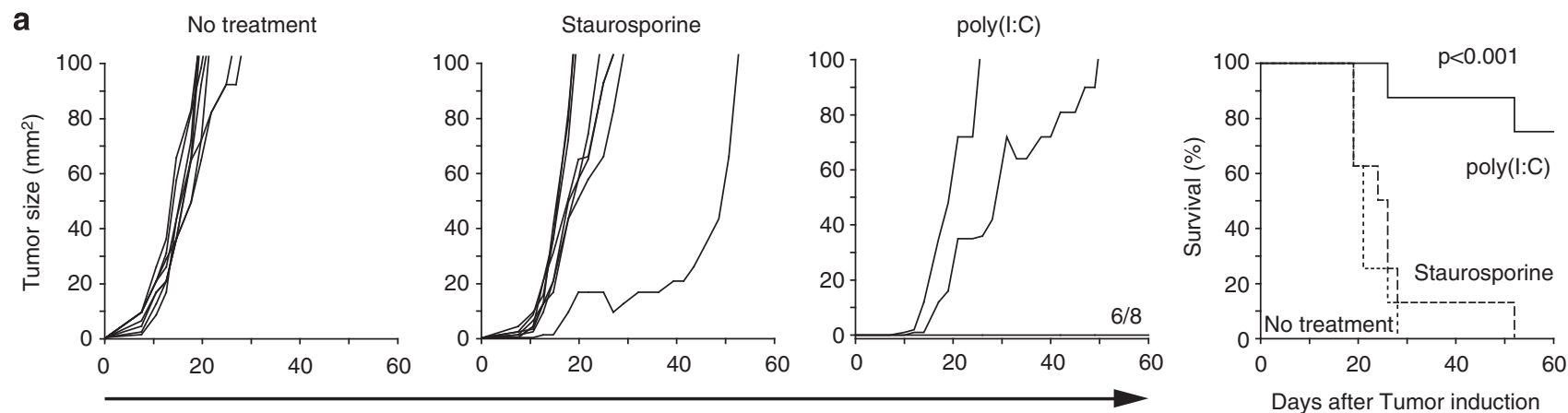

Days after tumor induction
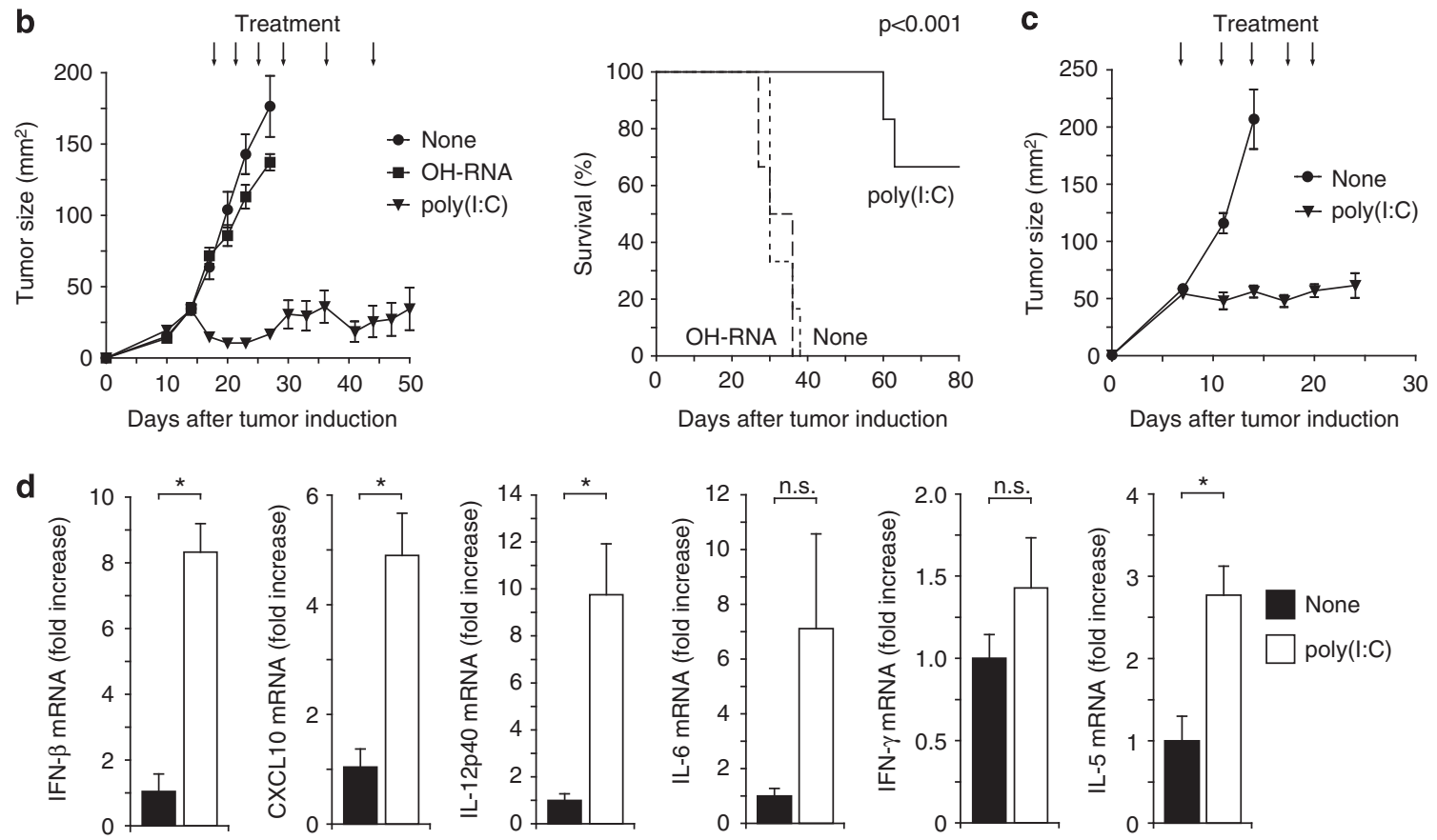

e $\quad \mathrm{CD} 8 \alpha^{+} \mathrm{CDC}$
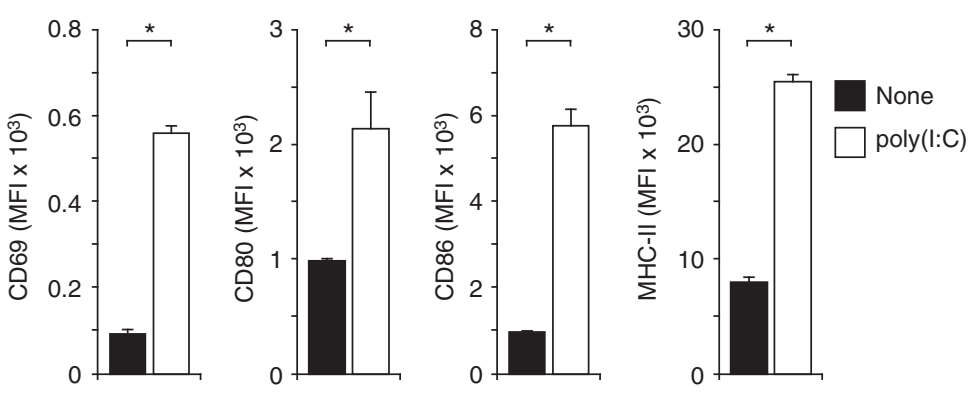

Figure 7 RLH-based immunotherapy mediates prophylactic and therapeutic antitumor immunity in vivo. (a) Prophylactic vaccination: Panc02 tumor cells were treated with staurosporine or transfected with poly(l:C) for $24 \mathrm{~h}$ in vitro. Nonadherent cells were harvested and counted. A total of $5 \times 10^{5}$ apoptotic tumor cells were injected s.c. into the left flank of C57BL/6 mice. Seven days later, mice where challenged with $5 \times 10^{5}$ viable Panc02 cells injected into the right flank. Tumor growth and survival was monitored for 60 days ( $n=8$ mice per group); (b and c) tumor therapy: established subcutaneous Panc02 (b) or T110299 (c) tumors (average size $50 \mathrm{~mm}^{2}$ ) were locally injected with $25 \mu \mathrm{g}$ of $\mathrm{OH}-\mathrm{RNA}$ or poly(l:C) complexed to in vivo-JetPEI. Injections were repeated twice weekly (arrows) for a total of up to six injections. Tumor growth was monitored daily and mice were killed when tumor size exceeded $150 \mathrm{~mm}^{2}$ or tumor showed ulcerations ( $n=8$ mice per group); (d) Panc02 tumors were removed $18 \mathrm{~h}$ after local treatment, homogenized and mRNA expression profiles were obtained by qRT-PCR $\left(n=3\right.$ mice per group); (e) surface marker expression of CD8 $\alpha^{+}$CD $11 c^{+}$DCs in spleen of treated mice was analyzed by flow cytometry ( $n=3$ mice per group). ${ }^{*} P<0.05$ 
Next, we investigated whether RLH ligands have antitumor efficacy in a therapeutic setting. To this end mice with palpable Panc02 tumors (average size $40 \mathrm{~mm}^{2}$ ) were treated with the MDA5 ligand poly(l:C) via intratumoral injection. As compared with mice that had received no treatment or a control RNA, the MDA5 ligand led to a decrease of tumor burden and significantly prolonged survival. Sixty-five percent mice survived during an observation period of 80 days without tumor progression, whereas all control mice had to be killed within 40 days (Figure 7b). Similar efficacy was observed for mice with T110299 tumors (Figure 7c).

To characterize the influence of MDA5-based treatment on tumor microenvironment we analyzed cytokine mRNA profiles in tumor tissue by qRT-PCR. These studies revealed increased expression levels of IFN- $\beta$, CXCL10, IL-12p40, IFN- $\gamma$ (NS), IL-6 (NS) and IL-5, indicative of a proinflammatory mixed Th1/Th2 profile (Figure 7d). Analysis of splenic CD $8 \alpha^{+}$ DCs in treated mice showed high expression levels of CD69, CD80, CD86 and MHC-II, indicative of a mature phenotype (Figure 7e). Together, these findings confirm the immunogenic properties of tumor cell death induced by RLH activation in vivo.

\section{Discussion}

A major hurdle for therapy of pancreatic cancer is overcoming tumor-induced immunosuppression. Suppression of adaptive immunity is mediated by inhibitory immune cell populations, which are increased in pancreatic cancer patients and correlate with a poor prognosis. ${ }^{5-7}$ Of note, type I IFNs decrease the suppressive function of both regulatory $\mathrm{T}_{\text {cells }}{ }^{34}$ and myeloid-derived suppressor cells. ${ }^{35}$ The rationale for $\mathrm{RLH}$-based tumor therapy is to mimic a viral infection for inducing a type I IFN-driven immune response with concomitant induction of tumor cell apoptosis. ${ }^{19,20,24}$ Our group recently reported on the potent therapeutic efficacy of a bi-functional siRNA targeting TGF- $\beta$ and RIG-I in a pancreatic cancer model, which was dependent on CD8 ${ }^{+}$T cells. $^{21}$ This study already indicated that RLH activation has the capacity to link innate with adaptive immunity when tumor-induced immunosuppression is effectively counteracted.

In the present study, using two different murine pancreatic cancer cell lines, we demonstrated that RLH activation leads to the expression of proinflammatory cytokines, including type I IFN, as well as apoptotic cell death. These findings are in line with previous reports demonstrating that $\mathrm{RLH}$ induce proapoptotic signaling via the intrinsic pathway, which involves proapoptotic $\mathrm{BH} 3-$ only proteins Puma and Noxa and requires Apaf-1 and caspase-9. ${ }^{19-21}$ In addition, MDA5 activation in melanoma cells has been shown to mount a stress response program leading to autophagy. ${ }^{28}$ Expression of LC3-II in RLH-activated Panc02 cells confirmed the involvement of autophagy in apoptotic cell death of pancreatic cancer cells. In addition, RLH signaling in tumor cells can lead to mitochondrial stress with ROS accumulation. ${ }^{20}$ Interestingly, both ER stress and autophagy are hallmarks of immunogenic cell death induced by chemotherapeutic drugs. ${ }^{36}$

DCs link innate and adaptive immunity by presenting exogenous antigen in the context of $\mathrm{MHC}$ molecules to
$\mathrm{T}$ cells, which is a prerequisite for efficient tumor immune control. Exposure of CD $8 \alpha^{+}$DCs to RLH-activated apoptotic tumor cells led to DC maturation, efficient antigen uptake and cross-presentation of tumor-associated antigen to CTL. In addition, vaccination with MDA5-activated apoptotic tumor cells protected mice from subsequent challenge with viable tumor cells, indicative of the emergence of an adaptive antitumor immune response in vivo. Thus, RLH-mediated cell death fulfills the typical criteria defining immunogenic cell death. ${ }^{13}$ Several substances, including the chemotherapeutic agent oxaliplatin, have been reported to induce immunogenic tumor cell death. ${ }^{37-39}$ However, in our study cell death induction of pancreatic cancer cells with oxaliplatin did neither induce DC activation nor facilitate antigen cross-presentation, despite effective tumor cell killing. Similarly, exposure of DCs to tumor cell lysates or staurosporine-treated tumor cells did not induce a productive immune response. Possibly, the potent immunosuppressive microenvironment inherent to pancreatic cancer cells forms a major hurdle that cannot be overcome by cytotoxic drugs.

This leads to the question of how RLH activation leads to immunogenic tumor cell death. A critical step in the induction of an adaptive immune response is activation of DCs, which can be mediated by several factors released by dying or damaged cells, collectively termed DAMP. ${ }^{12}$ A prominent DAMP that has been linked to immunogenic cell death is HMGB1, which activates DCs via TLR2/4 and RAGE receptors. ${ }^{40-44}$ Interestingly, we found that $\mathrm{RLH}$-activated tumor cells released high levels of HMGB1. However, we ruled out a significant contribution of HMGB1 or other endogenous TLR ligands to DC activation as DCs generated from mice deficient in specific TLR, TLR signaling pathways or RAGE showed unimpaired DC activation. Another pathway involved in immunogenic tumor cell death in response to cytotoxic agents is the NLRP3 inflammasome. ${ }^{33}$ We also ruled out an inflammasome-mediated mechanism by demonstrating normal DC activation in mice with defects in components of the inflammasome pathway, such as NLRP3, ASC, the P2X7 receptor or IL-18. As our studies indicated that DC activation is mediated by a soluble, heat-labile factor derived from tumor cells, we investigated the role of IFN signaling using type I IFN receptor (IFNAR) blocking mAb as well as IFNAR-deficient mice. These experiments revealed that tumor-derived type I IFN is critical for driving DC activation, although other factors seem to contribute, as exogenous IFN was less potent than activated tumor supernatant. How do these findings translate into the in vivo situation? We found that local injection of the MDA5 ligand poly $(\mathrm{I}: \mathrm{C})$ into established pancreatic tumors induced upregulation of type I IFN and other proinflammatory cytokines in tumor tissue, such as IL-12, IFN- $\gamma$, IL-6 and IL-5. This was accompanied by increased expression levels of costimulatory and $\mathrm{MHC}$ molecules by CD $8 \alpha^{+}$DCs. Type I IFN production by tumor cells may contribute to DC activation favoring Th1 polarization and the induction of tumor-specific adaptive immunity in vivo. Thus, tumor-derived type I IFN may link innate with adaptive immunity and contribute to overcoming tumor-induced immunosuppression, as evidenced by tumor regression and prolonged survival of mice with established tumors in two different pancreatic cancer models. 
Another interesting finding was that tumor cells treated with sublethal doses of RLH ligands upregulated MHC-I and Fas expression, which led to an increased sensitivity towards CTL- and Fas-mediated tumor cell killing. Thus, treatment with RLH ligands can - depending on dose and susceptibility of the tumor - induce either direct tumor cell apoptosis or facilitate tumor killing by pre-existing tumorreactive CTL. Both mechanisms may contribute to an ongoing adaptive immune response against the tumor by providing a source of tumor antigen for DCs (Supplementary Figure 3).

In conclusion, our study demonstrates that RLH ligands induce an immunogenic form of tumor cell death driven by type I IFN. Effective cross-presentation of tumor-associated antigen by DCs forms a basis for the rationale of employing $\mathrm{RLH}$ ligands either ex vivo to improve the potency of DCbased tumor vaccines or in vivo to directly prime antitumor CTL responses. In this regard, local treatment of potentially resectable pancreatic cancers with $\mathrm{RLH}$ ligands before surgery may facilitate the induction of a T-cell-mediated antitumor immune response with the potential to control outgrowth of residual tumor cells.

\section{Materials and Methods}

Mice. All animal studies were approved by the local regulatory agencies. Female C57BL/6 mice were obtained from Janvier and used at 6-8 weeks of age. $\mathrm{IL}-18^{-1-}$ and P2X7 $\mathrm{R}^{-1-}$ were purchased from Charles River (Wilmington, DE USA). Age- and sex-matched TLR2/4 ${ }^{-1-}, \mathrm{TLR}^{-1-}, \mathrm{TRIF}^{-1-}$ and MyD88 ${ }^{-1}$

mice on C57BL/6 background were kindly provided by Professor Jürgen Heesemann (Max-von-Pettenkofer Institute, LMU Munich, Germany); MDA5 ${ }^{-1-}$ mice by Professor Simon Rothenfusser (Department of Clinical Pharmacology, LMU Munich, Germany); NLRP3 ${ }^{-1-}$ mice by Professor Jürg Tschopp (formerly Department of Biochemistry, University of Lausanne, Lausanne, Switzerland); IRF$3 / 7^{-1-}$, ASC $^{-1-}$ and IFNAR ${ }^{-1-}$ (129Sv/Ev background) mice by Professor Hans-Joachim Anders (Medizinische Klinik und Poliklinik IV, LMU Munich, Germany); RAGE ${ }^{-1-}$ mice by Professor Markus Sperandio (Walter-BrendelCenter for Experimental Medicine, LMU Munich, Germany); OT-I mice by Professor Thomas Brocker (Institute for Immunology, LMU Munich, Germany). All experiments were performed as approved by the local ethics committee.

Cell lines and reagents. The murine Panc02 and PancOVA pancreatic cancer cell lines were generated and cultured as described before. ${ }^{21,45,46}$ The tumor cell line T110299 was developed from a primary pancreatic tumor of a Ptf1aCre;Kras ${ }^{\mathrm{G} 12 \mathrm{D}} ; \mathrm{p}^{\mathrm{ft} / \mathrm{R} 172 \mathrm{H}}$ mouse $^{25}$ and was kindly provided by Dr. Jens Siveke (Technical University of Munich, Munich, Germany). Fms-like tyrosine kinase 3 ligand (Flt3L)-transduced B16 melanoma cells were kindly provided by Professor Glenn Dranoff (Dana-Farber Cancer Institute, Boston, MA, USA). ${ }^{31}$ All cell lines were cultured in DMEM supplemented with 10\% FCS (Gibco, Darmstadt, Germany), $2 \mathrm{mM} \mathrm{L-glutamine,} 100 \mathrm{U} / \mathrm{l}$ penicillin and $0.1 \mathrm{mg} / \mathrm{ml}$ streptomycin (all PAA, Pasching, Austria). The PancOVA cell line, expressing the model antigen ovalbumin, was cultured with additional $1 \mathrm{mg} / \mathrm{ml}$ geneticin for selection purpose. Cross-presentation assays were performed in RPMI 1640 medium (Biochrom, Berlin, Germany) supplemented with 10\% FCS, $2 \mathrm{mM}$ L-glutamine, $100 \mathrm{U} / \mathrm{l}$ penicillin, $0.1 \mathrm{mg} / \mathrm{ml}$ streptomycin, $100 \mathrm{mM}$ nonessential amino acids, $1 \mathrm{mM}$ sodium pyruvate (all PAA, Pasching, Austria), $50 \mathrm{mM}$ 2-mercaptoethanol and $10 \mathrm{mM}$ HEPES (Sigma, Taufkirchen, Germany). Oxaliplatin was provided by the local hospital pharmacy. Staurosporine, benzonase, DNAse RNAse A, RNAse $\mathrm{H}$ and cycloheximide were obtained from Sigma; CpG ODN1826 and LPS from Invivogen (Toulouse, France); Cytochalasin D from Merck Millipore (Darmstadt, Germany). Recombinant murine IL-6 was from Immunotools (Friesoythe, Germany), murine IFN- $\alpha$ from Miltenyi Biotech (Bergisch Gladbach, Germany) and IFN- $\beta$ from BioLegend (London, UK).

Transfection of tumor cells. The ppp-RNA was generated by in vitro transcription as previously described, ${ }^{10,14,21}$ using the following DNA templates: sense $5^{\prime}$-TACGTAAGCTGGATAGCGCTATAGTGAGTCG-3' and antisense $5^{\prime}$-GCGCTATCCAGCTTACGTATATAGTGAGTCG-3'. The matching unspecific OH-RNA control sequence (sequence 5'-GCGCUAUCCAGCUUACGUAdTdT-3') was purchased from Eurofins (Ebersberg, Germany). The synthetic MDA5 ligand poly(l:C) (HMW) VacciGrade was purchased from Invivogen. Tumor cells were plated at $2.5 \times 10^{4}$ cells per well in 24-well plates overnight. Tumor cells were transfected with the indicated amounts of poly(l:C), ppp-RNA or OH-RNA using Lipofectamine RNAiMAX (Invitrogen, Darmstadt, Germany) according to the manufacturer's instructions. For DC activation and cross-presentation experiments, cells were stimulated with either $500 \mathrm{ng} / \mathrm{ml}$ poly $(\mathrm{l}: \mathrm{C}), 3 \mu \mathrm{g} / \mathrm{ml}$ ppp-RNA or equal amounts of OH-RNA as transfection control. Silencing of RIG-I and MDA5 before RNA stimulation was done as described before. ${ }^{21}$ Briefly, $48 \mathrm{~h}$ before stimulation, cells were transfected with $0.5 \mu \mathrm{g} / \mathrm{ml}$ of siRNA (Eurofins) specific for RIG-I (5'-GAAGCGUCUUCUAAUAAUUdTdT-3') or MDA5 (5'-GGUGCACAAAG GUUUAGAUdTdT-3').

Apoptosis detection by annexin V/PI staining. Apoptosis was determined 24 or $48 \mathrm{~h}$ after transfection of tumor cells with poly (l:C) or ppp-RNA, respectively, if not otherwise stated. Nonadherent and adherent cells were collected and stained with APC-conjugated annexin V (Immunotools). Propidium iodide (PI, Sigma) was added directly before analysis by flow cytometry. Cells staining negative for annexin V and propidium iodide (viable cells) are illustrated relatively to untreated tumor cells.

ELISA. Cytokines and chemokines secreted into cell culture supernatants were determined by ELISA according to the manufacturer's manual. ELISA kits for IL-6 were purchased from BD Biosciences (Heidelberg, Germany), CXCL10 and Hsp70 from R\&D Systems (Wiesbaden-Nordenstadt, Germany), and HMGB1 from IBL International (Hamburg, Germany).

Enrichment of splenic DCs. To drive a rapid expansion of primary DCs in vivo, we injected C57BL/6 mice subcutaneously with $5 \times 10^{6} \mathrm{Flt} 3 \mathrm{~L}$-transduced B16 melanoma cells. After 10-12 days, mice were killed and the spleens were cut into small fragments, minced into single-cell suspensions and leukocytes were isolated using Percoll (Biochrom) gradient centrifugation $\left(1.077 \mathrm{~g} / \mathrm{cm}^{3}\right)$ with $1.700 \times g$ at $4{ }^{\circ} \mathrm{C}$. DCs were further enriched by using the Dynabeads Mouse DC Enrichment Kit (Invitrogen) as described. ${ }^{47}$ For enrichment of DC subsets, biotinylated antibodies were added during magnetic bead separation to obtain total splenic DCs. For enrichment of the CD $8 \alpha^{+}$DC subset, we supplemented the kit-derived DC isolation antibody cocktail with biotinylated anti-CD4 (clone RM4-5), anti-B220 (clone RA3-6B2, both $2.25 \mu \mathrm{g} / 10^{7}$ cells; BioLegend, London, UK) and anti-CD172a (clone P84, $0.75 \mu \mathrm{g} / 10^{7}$ cells; eBioscience, Frankfurt, Germany); $\mathrm{CD} 8 \alpha^{-}$DCs were enriched by adding biotinylated anti-CD8 $\alpha$ (clone 53-6.7; BioLegend) and anti-B220 (both $2.25 \mu \mathrm{g} / 10^{7}$ cells). Purity was determined by flow cytometry using fluorochrome-conjugated antibodies against CD11c (APC, clone N418), B220 (PE-Cy.7, clone RA3-6B2) and CD8 $\alpha$ (PerCP, clone 53-6.7; all BioLegend) using FACS Canto II flow cytometer (BD). Purity was routinely $>90 \%$.

In vitro generation of Flt3L-induced dendritic cells. In vitro generation of $\mathrm{CD} 8 \alpha^{+}$equivalent dendritic cells was performed as described. ${ }^{48}$ Briefly, bone marrow of IFNAR ${ }^{-1}$ or wild-type mice of $129 \mathrm{~Sv} / \mathrm{Ev}$ background was extracted out of femur and tibia and further processed for red cell lysis. Cells were seeded at $2 \times 10^{6}$ cells $/ \mathrm{ml}$ and cultured in VLE-RPMI 1640 medium (Biochrom) supplemented with $300 \mathrm{ng} / \mathrm{ml}$ recombinant murine Flt3L (R\&D Systems) for 8 days. The CD24 hi/CD11b ${ }^{\text {low }}$ subset of CD11 $c^{\text {hi }} / C D 45 R A^{\text {neg }}$ cells was selected as $\mathrm{CD} 8 \alpha^{+}$equivalents of conventional DCs by flow cytometry.

Phagocytosis assay. Tumor cells were labeled with $2.5 \mu \mathrm{M}$ CFDA-SE (Sigma) and seeded at $2.5 \times 10^{4}$ cells per well in 24-well plates overnight before transfection with RLH ligands or treatment with cytotoxic drugs, as indicated. Total enriched splenic DCs were added and harvested after $3 \mathrm{~h}$. DCs were stained using antibodies against CD11C-APC, B220-PE-Cy7 and CD8 $\alpha$-PerCP. CFSE content of the particular DC subsets (CD8 $\alpha^{+}$DCs: CD11 $c^{\text {high }}, \mathrm{CD} 8 \alpha^{+} ; \mathrm{CD} 8 \alpha^{-}$DCs: CD11c high, $\mathrm{CD} 8 \alpha^{-}$, $\mathrm{B}_{22}{ }^{-}$; pDCs: $\mathrm{CD} 11 \mathrm{c}^{\text {int }}, \mathrm{B}_{220^{+}}$) was analyzed by flow cytometry.

Flow cytometry. Total enriched splenic DCs $\left(5 \times 10^{5}\right.$ cells/well) were cultured with or without tumor cells (or their supernatants) and harvested after $14 \mathrm{~h}$. DCs were stained using fluorochrome-conjugated antibodies to identify DC subsets (CD11C-Pacific Blue, B220-PE-Cy7 and CD8 $\alpha$-PerCP) and additionally 
stained for activation markers CD69 (FITC, clone H1.2F3; Invitrogen), CD80 (PE, clone 16-10A1) and CD86 (APC, clone GL-1; both BioLegend). Intracellular cytokine staining was performed from cocultures of tumor cells with previously enriched total splenic DCs over $6 \mathrm{~h}$ in the presence of $1 \mu \mathrm{g} / \mathrm{ml}$ Brefeldin A (Merck Millipore) for $5 \mathrm{~h}$. Cocultures were harvested and stained for DC subset makers. After fixation with paraformaldehyde and permeabilization with saponin (both Sigma), DCs were stained for IL-6 (PE, clone MP5-20F3; BioLegend) or goat anti-mouse CXCL10 (R\&D Systems). CXCL10 was further detected by donkey anti-goat Alexa-488 (Invitrogen). Where indicated, we expressed data as fold induction of the respective activation marker relative to the mean fluorescence intensity (MFI) of DCs cocultured with untreated Panc02 tumor cells using the formula: fold induction $=$ MFI (treated DCs)/MFI (untreated DCs). Panc02 tumor cells were surface-stained with anti-mouse MHC class I (FITC, clone AF6-88.5, Biolegend) or anti-mouse CD95 (Fas) (PE, clone Jo2, BD Biosciences). For measurement of calreticulin surface exposure, $5 \times 10^{4} \mathrm{Panc} 02$ cells were plated in a 24-well plate and stimulated with ppp-RNA, poly(l:C) or control RNA. Cells were incubated with $5 \mu \mathrm{g} / \mathrm{ml}$ rabbit anti-human/mouse calreticulin (clone RB21112, Biomol, Hamburg, Germany) for $15 \mathrm{~min}$ at $4{ }^{\circ} \mathrm{C}$. For intracellular calreticulin staining, cells were fixed with $2 \%$ paraformaldehyde for $10 \mathrm{~min}$ at RT and labeled with $5 \mu \mathrm{g} / \mathrm{ml}$ anti-calreticulin in $0.5 \%$ saponine (positive control). Fluorochrome staining was done using goat anti-rabbit lgG FITC secondary antibody (Invitrogen).

Western blot. Panc02 cells were treated for $24 \mathrm{~h}$ with ppp-RNA, control $\mathrm{OH}$ RNA or left untreated. PARP-1, RIG-I, MDA5 and LC3B-I/II were assessed in cell lysates with SDS-PAGE and detected using rabbit anti-mouse PARP-1 (New England Biolabs, Frankfurt, Germany), rabbit anti-mouse RIG-I (New England Biolabs), rabbit anti-mouse MDA-5 (Enzo Life Sciences, Lörrach, Germany) or rabbit anti-mouse LC3B (New England Biolabs). Anti-rabbit coupled to horseradish peroxidase served as secondary antibody (Santa Cruz Biotechnology, Heidelberg, Germany). Visualization was performed with ECL substrate and captured with an image Reader (LAS-4000, Fujitsu).

Confocal microscopy. Cells were plated onto microscope glass bottom dishes (Mat tek) and treated with ppp-RNA, control OH-RNA or left untreated for $24 \mathrm{~h}$. Activated caspase-9 of treated Panc02 tumor cells was assessed using Green FLICA Caspase-9 Assay kit (Biomol) according to the manufacturer's manual. Cells were costained with Alexa Fluor 647 cholera toxin subunit B (Invitrogen) for cell surface membrane and DAPI for nucleic staining. Cells were visualized with a Lyca SP5 confocal microscopy. For detection of membrane calreticulin, Panc02 cells were treated with poly(l:C) as indicated for different time points. Surface staining was done using rabbit anti-mouse calreticulin (Biomol). Alexa Fluor 488-conjugated goat anti-rabbit antibody served as secondary staining for FACS analysis.

Cytotoxicity assay. A total of $2 \times 10^{4}$ PancOVA cells were incubated for $16 \mathrm{~h}$ with immunostimulatory RNA, control OH-RNA or left untreated. Tumor cells were then cocultured with OT-I T cells at an E/T ratio of $5: 1$ for $6 \mathrm{~h}$ and specific lysis was assessed using the CytoTox 96 nonradioactive cytotoxicity assay (Promega, Mannheim, Germany) according to the manufacturer's protocol.

Inhibitor studies. For inhibitor studies, Panc02 tumor cells were incubated for $30 \mathrm{~min}$ with the indicated amounts of cycloheximide (CHX; Sigma). Cells were washed with PBS and stimulated with $0.5 \mu \mathrm{g} / \mathrm{ml}$ poly(l:C) before adding DCs to Panc02 tumor cells for coculture experiments. To block tumor-derived type I IFN, DCs were incubated with $5 \mu \mathrm{g} / \mathrm{ml}$ anti-IFNAR mAb (clone MAR1-5A3) or the appropriate $\lg \mathrm{G}$ control $\mathrm{Ab}$ (both BioLegend) for $2 \mathrm{~h}$ before treatment of $\mathrm{DCs}$ with tumor cell supernatant.

Cross-presentation assays. Enriched $\mathrm{CD} 8 \alpha^{-}$or $\mathrm{CD} 8 \alpha^{+} \mathrm{DCs}$ were added onto RLH ligand-treated tumor cell cultures for $12 \mathrm{~h}$. DCs were removed by gently rinsing the cultures with culture medium for coculture with OT-I T cells. Contaminating tumor cells were $<3 \%$, as determined by flow cytometry with CFSE-labeled tumor cells. OT-I T cells were enriched by magnetic separation using $\mathrm{CD}^{+}{ }^{+} \mathrm{T}$ Cell Isolation Kit II (Miltenyi Biotech) and labeled with CFSE as previously described. ${ }^{44}$ Finally, $10^{5}$ DCs were cocultured with $10^{5}$ OT-I T cells in 96-well round bottom wells for 3 days. DCs pulsed with SIINFEKL peptide ( $1 \mu \mathrm{g} / \mathrm{ml}$; JPT Peptide Technologies GmbH, Berlin, Germany) served as positive control. Numbers of proliferating OT-I T cells were quantified using Sphero calibration particles (BD Bioscience). ${ }^{47}$ Determination of SIINFEKL on $\mathrm{H}-2 \mathrm{~Kb}$
(MHC-I) was done by using anti-mouse OVA257-264 peptide bound to $\mathrm{H}-2 \mathrm{~Kb}$ $\mathrm{APC} A \mathrm{Ab}$ (clone 25-D1.16; BioLegend) by flow cytometry.

Prophylactic vaccinations and tumor therapy. For prophylactic vaccinations mice were injected s.c. into the left flank with $5 \times 10^{5}$ apoptotic Panc02 tumor cells that had been treated for $24 \mathrm{~h}$ with poly $(\mathrm{l}: \mathrm{C})$ or staurosporine. Seven days later, mice were challenged with $5 \times 10^{5}$ viable Panc02 cells injected into the right flank and tumor growth was monitored. For therapeutic experiments subcutaneous Panc02 or T110299 tumors were induced and locally injected with $25 \mu \mathrm{g}$ of OH-RNA or poly(l:C) complexed with in vivo-JetPEl (Peqlab, Erlangen, Germany) at an N/P ratio of 6 in $5 \%$ glucose solution when tumors had reached an average size of approximately $50 \mathrm{~mm}^{2}$. Injections were repeated twice weekly for a total of six injections. Tumor growth of mice was monitored daily and mice were killed upon appearance of distress, tumor ulcerations or tumor size exceeding $150 \mathrm{~mm}^{2}$.

RNA isolation and qRT-PCR. Tumor tissue was snap frozen in liquid nitrogen and homogenized using mortar and pestle. Homogenate was processed for total RNA isolation using peqGOLD Total RNA Kit (Peqlab) according to manufacturer's protocol. RNA was adjusted and transcribed into cDNA with the RevertAid First Strand cDNA Synthesis Kit (Fisher Scientific, Schwerte, Germany). qPCR was done with the Kapa Probe Fast Universal kit (Peqlab) on the LightCycler 480 II instrument (Roche, Mannheim, Germany) and samples were correlated to HPRT. Primers were designed with Roche's Universal Probes library.

Statistical analysis. Data present means + S.D. (in vitro data) or + S.E.M. (in vivo data). Significant differences were analyzed using two-tailed Student's $t$-test. Multiple comparisons were analyzed by one-way ANOVA including Bonferroni correction. Survival curves were analyzed with Mantel-Cox test. Statistical analysis was performed using GraphPad Prism software (version 5.0a); $P$-values $<0.05$ were considered significant.

\section{Conflict of Interest}

The authors declare no conflict of interest.

Acknowledgements. This work is part of the theses of AS, HL, HB, SB and MRS at the University of Munich. This work was supported by the Deutsche Forschungsgemeinschaft SCHN 664/3-1 and SCHN 664/3-2 to MS and GK 1202 to MS and SE, and GK 1202 student grants to AS, MRS and HB. We thank Dr. Sabine Hoves, Roche Diagnostics GmbH, Penzberg, for critical discussions.

1. Siegel R, Naishadham D, Jemal A. Cancer statistics, 2013. CA Cancer J Clin 2013; 63: 11-30.

2. Fatima J, Schnelldorfer T, Barton J, Wood CM, Wiste HJ, Smyrk TC et al. Pancreatoduodenectomy for ductal adenocarcinoma: implications of positive margin on survival. Arch Surg 2010; 145: 167-172.

3. Zheng L, Xue J, Jaffee EM, Habtezion A. Role of immune cells and immune-based therapies in pancreatitis and pancreatic ductal adenocarcinoma. Gastroenterology 2013; 144: $1230-1240$.

4. Rabinovich GA, Gabrilovich D, Sotomayor EM. Immunosuppressive strategies that are mediated by tumor cells. Annu Rev Immunol 2007; 25: 267-296.

5. Gabitass RF, Annels NE, Stocken DD, Pandha HA, Middleton GW. Elevated myeloidderived suppressor cells in pancreatic, esophageal and gastric cancer are an independent prognostic factor and are associated with significant elevation of the Th2 cytokine interleukin-13. Cancer Immunol Immunother 2011; 60: 1419-1430.

6. Hiraoka N, Onozato K, Kosuge T, Hirohashi S. Prevalence of FOXP3 + regulatory T cells increases during the progression of pancreatic ductal adenocarcinoma and its premalignant lesions. Clin Cancer Res 2006; 12: 5423-5434.

7. Liyanage UK, Moore TT, Joo HG, Tanaka Y, Herrmann V, Doherty G et al. Prevalence of regulatory $T$ cells is increased in peripheral blood and tumor microenvironment of patients with pancreas or breast adenocarcinoma. J Immunol 2002; 169: 2756-2761.

8. von Bernstorff W, Voss M, Freichel S, Schmid A, Vogel I, Johnk C et al. Systemic and local immunosuppression in pancreatic cancer patients. Clin Cancer Res 2001; 7(3 Suppl): 925s-932s.

9. Fukunaga A, Miyamoto M, Cho Y, Murakami S, Kawarada Y, Oshikiri T et al. $\mathrm{CD} 8+$ tumor-infiltrating lymphocytes together with $\mathrm{CD} 4+$ tumor-infiltrating lymphocytes and dendritic cells improve the prognosis of patients with pancreatic adenocarcinoma. Pancreas 2004; 28: e26-e31. 
10. Krysko DV, Garg AD, Kaczmarek A, Krysko O, Agostinis $P$, Vandenabeele $P$. Immunogenic cell death and DAMPs in cancer therapy. Nat Rev Cancer 2012; 12 860-875.

11. Zitvogel L, Apetoh L, Ghiringhelli F, Kroemer G. Immunological aspects of cancer chemotherapy. Nat Rev 2008; 8: 59-73.

12. Rock KL, Lai JJ, Kono H. Innate and adaptive immune responses to cell death. Immunol Rev 2011; 243: 191-205

13. Kroemer G, Galluzzi L, Kepp O, Zitvogel L. Immunogenic cell death in cancer therapy. Annu Rev Immunol 2013; 31: 51-72.

14. Gitlin L, Barchet W, Gilfillan S, Cella M, Beutler B, Flavell RA et al. Essential role of mda-5 in type I IFN responses to polyriboinosinic:polyribocytidylic acid and encephalomyocarditis picornavirus. Proc Natl Acad Sci USA 2006; 103: 8459-8464

15. Hornung V, Ellegast J, Kim S, Brzozka K, Jung A, Kato H et al. 5'-Triphosphate RNA is the ligand for RIG-I. Science 2006; 314: 994-997.

16. Pichlmair A, Schulz O, Tan CP, Naslund TI, Liljestrom P, Weber F et al. RIG-I-mediated antiviral responses to single-stranded RNA bearing 5'-phosphates. Science 2006; 314 997-1001.

17. Loo YM, Gale Jr M. Immune signaling by RIG-I-like receptors. Immunity 2011; 34 680-692.

18. Schmidt A, Rothenfusser S, Hopfner KP. Sensing of viral nucleic acids by RIG-I: from translocation to translation. Eur J Cell Biol 2012; 91: 78-85.

19. Besch R, Poeck H, Hohenauer T, Senft D, Hacker G, Berking C et al. Proapoptotic signaling induced by RIG-I and MDA-5 results in type I interferon-independent apoptosis in human melanoma cells. J Clin Invest 2009; 119: 2399-2411.

20. Meng G, Xia M, Xu C, Yuan D, Schnurr M, Wei J. Multifunctional antitumor molecule 5'-triphosphate siRNA combining glutaminase silencing and RIG-I activation. Int $\mathrm{J}$ Cancer 2013; 134: 1958-1971.

21. Ellermeier J, Wei J, Duewell P, Hoves S, Stieg MR, Adunka T et al. Therapeutic efficacy of bifunctional siRNA combining TGF-beta1 silencing with RIG-I activation in pancreatic cancer. Cancer Res 2013; 73: 1709-1720.

22. Kubler K, Gehrke N, Riemann S, Bohnert V, Zillinger T, Hartmann E et al. Targeted activation of RNA helicase retinoic acid-inducible gene-I induces proimmunogenic apoptosis of human ovarian cancer cells. Cancer Res 2010; 70: 5293-5304.

23. Kubler K, tho Pesch C, Gehrke N, Riemann S, Dassler J, Coch C et al. Immunogenic cell death of human ovarian cancer cells induced by cytosolic poly $(l: C)$ leads to myeloid cell maturation and activates NK cells. Eur J Immunol 2011; 41: 3028-3039.

24. Poeck H, Besch R, Maihoefer C, Renn M, Tormo D, Morskaya SS et al. 5'-TriphosphatesiRNA: turning gene silencing and Rig-I activation against melanoma. Nat Med 2008; 14 1256-1263.

25. Hingorani SR, Wang L, Multani AS, Combs C, Deramaudt TB, Hruban RH et al. Trp53R172H and KrasG12D cooperate to promote chromosomal instability and widely metastatic pancreatic ductal adenocarcinoma in mice. Cancer Cell 2005; 7: 469-483.

26. Nicholson DW, Ali A, Thornberry NA, Vaillancourt JP, Ding CK, Gallant M et al. Identification and inhibition of the ICE/CED-3 protease necessary for mammalian apoptosis. Nature 1995; 376: 37-43.

27. Tewari M, Quan LT, O'Rourke K, Desnoyers S, Zeng Z, Beidler DR et al Yama/CPP32 beta, a mammalian homolog of CED-3, is a CrmA-inhibitable protease that cleaves the death substrate poly(ADP-ribose) polymerase. Cell 1995; 81: 801-809.

28. Tormo D, Checinska A, Alonso-Curbelo D, Perez-Guijarro E, Canon E, Riveiro-Falkenbach E et al. Targeted activation of innate immunity for therapeutic induction of autophagy and apoptosis in melanoma cells. Cancer Cell 2009; 16: 103-114.
29. Obeid M, Tesniere A, Ghiringhelli F, Fimia GM, Apetoh L, Perfettini JL et al. Calreticulin exposure dictates the immunogenicity of cancer cell death. Nature Med 2007; 13: 54-61.

30. Dresch C, Leverrier Y, Marvel J, Shortman K. Development of antigen cross-presentation capacity in dendritic cells. Trends Immunol 2012; 33: 381-388.

31. Mach N, Gillessen S, Wilson SB, Sheehan C, Mihm M, Dranoff G. Differences in dendritic cells stimulated in vivo by tumors engineered to secrete granulocyte-macrophage colony-stimulating factor or Flt3-ligand. Cancer Res 2000; 60: 3239-3246.

32. Sims GP, Rowe DC, Rietdijk ST, Herbst R, Coyle AJ. HMGB1 and RAGE in inflammation and cancer. Annu Rev Immunol 2010; 28: 367-388.

33. Ghiringhelli F, Apetoh L, Tesniere A, Aymeric L, Ma Y, Ortiz C et al. Activation of the NLRP3 inflammasome in dendritic cells induces IL-1beta-dependent adaptive immunity against tumors. Nature Med 2009; 15: 1170-1178.

34. Pace L, Vitale S, Dettori B, Palombi C, La Sorsa V, Belardelli F et al. APC activation by IFN-alpha decreases regulatory T cell and enhances Th cell functions. J Immunol 2010; 184: 5969-5979.

35. Zoglmeier C, Bauer $H$, Norenberg D, Wedekind G, Bittner $P$, Sandholzer N et al. $\mathrm{CpG}$ blocks immunosuppression by myeloid-derived suppressor cells in tumor-bearing mice. Clin Cancer Res 2011; 17: 1765-1775.

36. Garg AD, Martin S, Golab J, Agostinis P. Danger signalling during cancer cell death: origins, plasticity and regulation. Cell Death Differ 2014; 21: 26-38.

37. Ma Y, Aymeric L, Locher C, Mattarollo SR, Delahaye NF, Pereira P et al. Contribution of IL-17-producing gamma delta $T$ cells to the efficacy of anticancer chemotherapy. J Exp Med 2011; 208: 491-503.

38. Panaretakis T, Kepp O, Brockmeier U, Tesniere A, Bjorklund AC, Chapman DC et al. Mechanisms of pre-apoptotic calreticulin exposure in immunogenic cell death. EMBO J 2009; 28: 578-590.

39. Tesniere A, Schlemmer F, Boige V, Kepp O, Martins I, Ghiringhelli F et al. Immunogenic death of colon cancer cells treated with oxaliplatin. Oncogene 2009; 29: 482-491.

40. Apetoh L, Ghiringhelli F, Tesniere A, Obeid M, Ortiz C, Criollo A et al. Toll-like receptor 4-dependent contribution of the immune system to anticancer chemotherapy and radiotherapy. Nature Med 2007; 13: 1050-1059.

41. Curtin JF, Liu N, Candolfi M, Xiong W, Assi H, Yagiz K et al. HMGB1 mediates endogenous TLR2 activation and brain tumor regression. PLoS Med 2009; 6: e10.

42. Dumitriu IE, Baruah P, Bianchi ME, Manfredi AA, Rovere-Querini P. Requirement of HMGB1 and RAGE for the maturation of human plasmacytoid dendritic cells. Eur $J$ Immunol 2005; 35: 2184-2190.

43. Rovere-Querini P, Capobianco A, Scaffidi P, Valentinis B, Catalanotti F, Giazzon M et al. HMGB1 is an endogenous immune adjuvant released by necrotic cells. EMBO Rep 2004; 5: $825-830$.

44. Tian J, Avalos AM, Mao SY, Chen B, Senthil K, Wu H et al. Toll-like receptor 9-dependent activation by DNA-containing immune complexes is mediated by HMGB1 and RAGE. Nature Immunol 2007; 8: 487-496.

45. Corbett TH, Roberts BJ, Leopold WR, Peckham JC, Wilkoff LJ, Griswold Jr DP. et al. Induction and chemotherapeutic response of two transplantable ductal adenocarcinomas of the pancreas in C57BL/6 mice. Cancer Res 1984; 44: 717-726.

46. Jacobs C, Duewell P, Heckelsmiller K, Wei J, Bauernfeind F, Ellermeier J et al. An ISCOM vaccine combined with a TLR9 agonist breaks immune evasion mediated by regulatory T cells in an orthotopic model of pancreatic carcinoma. Int J Cancer 2011; 128: 897-907.

47. Hoves S, Sutton VR, Haynes NM, Hawkins ED, Fernandez Ruiz D, Baschuk N et al. A critical role for granzymes in antigen cross-presentation through regulating phagocytosis of killed tumor cells. J Immunol 2011; 187: 1166-1175.

48. Naik SH, Proietto Al, Wilson NS, Dakic A, Schnorrer P, Fuchsberger M et al. Cutting edge: generation of splenic CD8 + and CD8- dendritic cell equivalents in Fms-like tyrosine kinase 3 ligand bone marrow cultures. J Immunol 2005; 174: 6592-6597.

\section{Supplementary Information accompanies this paper on Cell Death and Differentiation website (http://www.nature.com/cdd)}

